\title{
Implementing change in health services: the case of rapid response systems
}

\section{Carolien de Blok* and Ellen S. Koster}

NIVEL - Netherlands Institute for Health Services Research, P.O. Box 1568, 3500 BN Utrecht, The Netherlands

E-mail: c.deblok@nivel.nl

E-mail: e.koster@uu.nl

*Corresponding author

\section{Cordula Wagner}

NIVEL - Netherlands Institute for Health Services Research, P.O. Box 1568, 3500 BN Utrecht, The Netherlands

and

EMGO Institute,

VU University Medical Centre,

Amsterdam, the Netherlands

E-mail: c.wagner@nivel.nl

\begin{abstract}
Rapid response systems (RRSs) have been introduced in hospitals to prevent delays in medical management of care for patients whose clinical status deteriorates unexpectedly. An RRS consists of three limbs and its implementation affects the entire hospital organisation. This paper aims to provide insights into the approaches used by Dutch hospitals for RRS implementation and the factors influencing the approaches chosen. Starting from a conceptual framework emphasising the importance of the process, content and context for innovation implementation, our qualitative study shows the breadth of approaches used in practice. In-depth insights into the implementation process, content and context - as well as the relationships between them - extend existing theory on RRS implementation and will help hospitals tailor their implementation approach to organisational characteristics.
\end{abstract}

Keywords: rapid response system; RRS; healthcare innovation; implementation strategy; qualitative research; healthcare organisation.

Reference to this paper should be made as follows: de Blok, C., Koster, E.S. and Wagner, C. (2013) 'Implementing change in health services: the case of rapid response systems', Int. J. Organisational Design and Engineering, Vol. 3, No. 1, pp.1-34.

Biographical notes: Carolien de Blok is appointed at NIVEL as a postdoctoral researcher on quality and safety in the healthcare field. Her research interests include: quality and safety of care, organisation of care processes for complex patients, patient and information handover and related topics.

Ellen S. Koster was appointed at NIVEL as a postdoctoral researcher on patient safety in hospitals up to November 2012. Her research interests include: patient safety, medication safety (pharmaco)epidemiology, medication adherence and related topics. 
Cordula Wagner is the Head of the programme quality and organisation of cure and care at NIVEL and Professor of Patient Safety at VU University Medical Center. Her research centres around quality management systems, detection and prevention of adverse healthcare outcomes and improvement of healthcare processes.

This paper is a revised and expanded version of a paper entitled 'Implementing change in health services' presented at the 19th International Annual EurOMA Conference, Amsterdam, 2012.

\section{Introduction}

Over the last century, thorough thinking about process and system design has greatly improved the responsiveness, flexibility and efficiency of manufacturing and services. It has been recognised that similar ways of thinking about and delivering healthcare services would be extremely valuable for quality improvement (Walley, 2003; Morton and Cornwell, 2009). To arrive at desired changes, application of comprehensive concepts such as focused factories (e.g., Casalino et al., 2003; Hyer et al., 2009) and total quality management (Øvretveit, 2000; Shortell et al., 2000; Gregori et al., 2009) have been emphasised by academics and hospitals. However, successful implementation of new concepts is a prerequisite if improvements in process and patient outcomes are to be achieved. Research has shown that the implementation of comprehensive concepts requires more than just a focus on the contents of the concept itself (i.e., what the concept encompasses and its objectives). The process of implementation (i.e., how change is achieved, what activities are done and by whom) and the context of the organisation (internal and external factors such as culture and politics that influence change) also have to be taken into account (Pettigrew and Whipp, 1993).

One concept that aims to improve the quality of care delivered by hospitals is the rapid response system (RRS). This is a hospital-wide care system focusing on providing appropriate care to ward patients whose vital functions (heart rate, respiration rate, consciousness) deteriorate unexpectedly. RRSs are built around a specialised team of caregivers - the rapid response team - that can be called to the hospital wards in acute situations to treat patients suffering from clinical deterioration (Winters et al., 2007). The team is complemented by different types of procedures, for example for early recognition of clinical deterioration on hospital wards. Through early recognition of deteriorating patients and the provision of immediate and suitable care to these patients, the RRS aims to reduce unplanned intensive care unit (ICU) transfers, cardiopulmonary resuscitation (CPR) and possible deaths of these patients.

RRSs have been implemented in Australia, the UK and the USA (Winters et al., 2007; Jones et al., 2011) and they are now becoming common in Scandinavian countries and the Netherlands. Despite conflicting evidence about RRS effectiveness (Chan et al., 2008, 2010), its introduction has been driven by the belief that an RRS prevents serious adverse events after sudden alterations in vital signs in hospital ward patients, thus making the hospital a safer environment for patients (Jones et al., 2011). This, however, requires implementation of the concept and compliance with its way of working on all hospital wards (Jones et al., 2011). 
A complete RRS comprises three main components (Winters et al., 2007; Jones et al., 2011). The first is the efferent limb, a rapid response team (RRT) that is often set up at the ICU. This team can be called by hospital wards when a patient's vital functions suddenly deteriorate. The team responds to calls by sending appropriate personnel and equipment to the ward. The second component is the afferent limb, which is designed to identify clinical deterioration in patients on the wards and trigger a response. It includes procedures for early recognition of patient deterioration through evaluation of vital signs (such as heart rate, respiration rate or consciousness) and the criteria for calling the RRT to be used by ward nurses. The third component provides a hospital-wide feedback loop, which includes the collection of data and analysis of events where the RRT was called in. Reviewing data on RRT calls and their outcomes might permit strategies to be developed that prevent clinical deterioration of patients and optimise care provision on hospital wards, thus allowing for continuous improvement of the care system (Jones et al., 2011). The implementation of an RRS will therefore influence many aspects of the hospital organisation, from the ICU to the wards and from operational to strategic levels.

Several success factors have been identified for the hospital context in which the RRS is to be implemented, such as hospital management support (DeVita et al., 2005) and having the right RRT leader (Jones et al., 2009). Given the content of the RRS, it has been recognised that hospitals with a teaching status choose different setups for their RRS compared to non-teaching hospitals, as hospitals tailor their RRS to meet the burden of events (more versus less complex patients) and incorporate the most appropriately trained personnel available (Jones and Bellomo, 2011). Teaching and university hospitals tend to set up a comprehensive system that is active $24 / 7$ to meet the needs of their complex patients and because they have highly trained (ICU) staff available. Smaller general hospitals may not have these kinds of facilities or have less complex patients and therefore choose a simpler team construction, daytime activation only, or restrict the number of wards to which RRT service is available.

Despite existing knowledge about RRS content and some insights into contextual factors, a comprehensive picture of the implementation process of RRSs and why hospitals choose their particular implementation approach is currently not known (DeVita and Hillman, 2011). Klein and colleagues (Klein and Knight, 2005; Klein and Sorra, 1996) emphasise that implementation is the crucial stage that moves from the decision to adopt an innovation on to the routine use of that innovation in practice. While innovation adoption has been widely studied, the implementation process has been less studied (Klein et al., 2001). Fixsen et al. (2005) call for studies that can increase knowledge about the process of implementation and offer practical guidance for both policy makers and service providers. To this end, they suggest the use of field-based approaches.

In response to the literature gaps identified by Klein and colleagues (Klein and Knight, 2005; Klein et al., 2001; Klein and Sorra, 1996) and Fixsen et al. (2005), this study aims to explore the concept of the RRS from the point of view of an implementation process. Using qualitative research reflecting on actual practice in Dutch hospitals let us increase knowledge about the process of implementation in real-life contexts. To guide data collection and analysis, we focused particularly on the implementation process in relation to the content of the innovation and the context in which the implementation process was taking place (Pettigrew and Whipp, 1993). To this end, the research question addressed by means of semi-structured interviews is "What approaches do hospitals follow when implementing RRSs and how do context, content and process factors influence the approach chosen?" 


\section{The process of innovation implementation in healthcare}

Innovation in care contexts has been defined as "a novel set of behaviours, routines and ways of working that are directed at improving health outcomes and that are implemented by planned and coordinated actions" (Greenhalgh et al., 2004). Innovations can be characterised by different degrees of newness for the context in which they are implemented, such as being new to the world, new to the industry or market, or new to the firm (e.g., Garcia and Calantone, 2002). 'New to the world' implies that something has been completely newly invented and never been used before, such as the World Wide Web or the discovery of penicillin. 'New to the industry or market' means that an innovation has been used in other sectors but it is newly introduced in the sector being focused on, such as the introduction in hospitals of crew resource management, which was originally developed in the airline sector. 'New to the firm' implies that an organisation is embracing a new way of working that might have proven itself already in other organisations in the same sector. Examples are the implementation of focused patient processes developed by, e.g., the Shouldice hospital for patients suffering from an external abdominal hernia or integrated care processes developed by Mayo Clinics, or the implementation of a RRS in hospitals. In this paper, we are focusing on the last of the three, i.e., new to the firm.

Implementation of an innovation in an organisation is the process of gaining targeted employees' appropriate and committed use of an innovation (Klein and Sorra, 1996; Klein and Knight, 2005). The implementation process consists of various stages (e.g., Klein and Sorra, 1996; Greenhalgh et al., 2004; Hansen and Birkinshaw, 2007; Simpson and Flynn, 2008). In early stages of the implementation process, an innovation is adopted, i.e., a decision is made to adopt the innovation. Users are trained and the first actions are taken to introduce and use the innovation (Simpson and Flynn, 2008). In later stages of the implementation process, further actions are taken to spread the use of the innovation with the final aim of sustaining or 'routinising' the innovation (Simpson and Flynn, 2008). This means that the innovation is embedded in the organisation and put into practice by targeted users in a consistent manner (Greenhalgh et al., 2004).

In order to adopt an innovation within an organisation, various success factors have been identified in the literature that are related to the innovation itself, to the organisation in which the implementation is implemented and to the staff and professionals working in the organisation. As regards the innovation itself, its perceived quality and utility and the perceived possibility of adapting an innovation to the specific setting that it will be implemented in are crucial to innovation adoption (Simpson and Flynn, 2008). In terms of the staff, appropriate skills and abilities are required (Simpson and Flynn, 2008; Greenhalgh et al., 2004; Klein and Knight, 2005). At the organisational level it has been recognised that a supportive package of implementation practices is required, including resources (both time and money), training and a plan of action for implementation (Greenhalgh et al., 2004; Klein and Knight, 2005), as well as leadership support (Simpson and Flynn, 2008).

To achieve routinisation, staff need to be motivated and have the skills to use the innovation (Greenhalgh et al., 2004). To this end, the innovation itself has to be perceived as being effective and feasible (Simpson and Flynn, 2008) and empirical evidence and feedback has to be communicated among staff involved to prove the value of an innovation. At the organisational level, the availability of resources has been identified as being important for routinisation (Greenhalgh et al., 2004; Simpson and Flynn, 2008). 
In order to achieve innovation adoption as well as routinisation multiple factors are therefore involved that concern the content, i.e., the innovation itself (utility, adaptability, effectiveness and feasibility), as well as the context, i.e., staff having to work with the innovation (skills, motivation, communication) and the organisation in which the innovation is to be implemented (resources, training, leadership).

The process of innovation as depicted in the previous sections, including the adoption and routinisation phases and the content and context related factors influencing these phases of the implementation process, is summarised in Figure 1. This figure was adapted from Simpson and Flynn (2008) and will be used as a framework for focusing and organising the data collection and analysis in the remainder of this paper.

Figure 1 Framework for innovation implementation (see online version for colours)

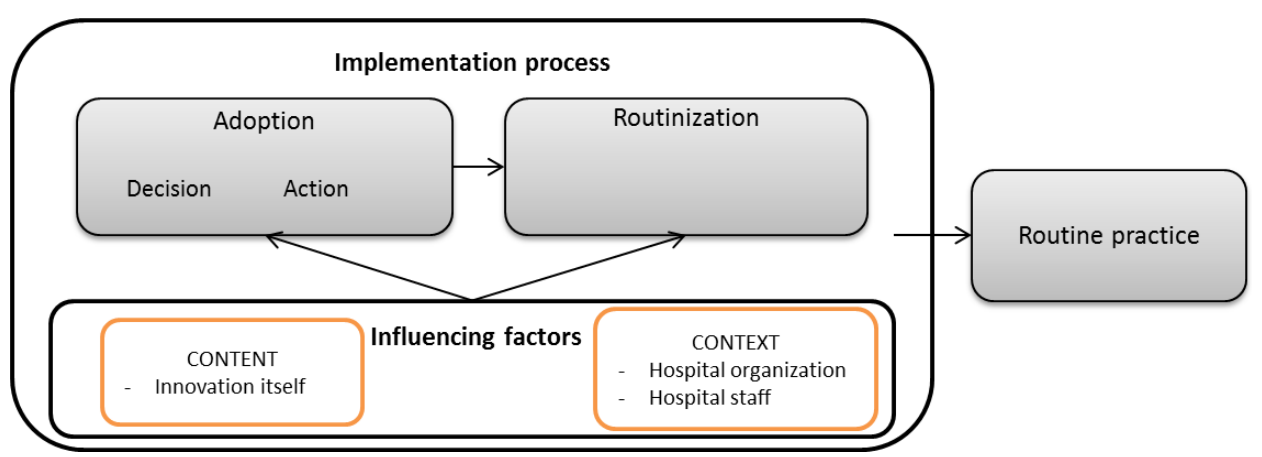

As yet, not much has been written about RRS adoption and routinisation. DeVita and Hillman (2011) identified that there is no strong data for defining particular strategies for RRS implementation; only the experiences of individual hospitals have been described. These experiences pointed to the importance of the use of data about the effectiveness of the RRS in the routinisation phase (DeVita and Hillman, 2011), for example, thereby confirming Simpson and Flynn (2008) in this specific context. Following the general insights on the implementation process that have been identified in various healthcare contexts (Greenhalgh et al., 2004; Simpson and Flynn, 2008), we posit that the process for RRS implementation also consists of various stages, in which adoption of the RRS is followed by its routinisation. In addition, we posit the importance of the innovation contents and implementation context in addition to the implementation process. In the remainder of this paper, we will shed further light upon the process of RRS implementation (including influencing factors) by using semi-structured interviews and thematic analysis, thereby working towards a more detailed understanding of the framework as presented in Figure 1 in the light of RRS implementation.

\section{Methodology}

The Netherlands has 91 hospitals: eight university hospitals with a teaching function, 27 teaching hospitals and 56 general hospitals without a teaching function (Dutch Hospital Data, 2012). Patient safety and quality improvement have been a major focus of the sector for years. Hospital associations, in collaboration with the Dutch government, 
introduced a nationwide Hospital Patient Safety Programme in 2008 to give more impetus to this trend. As part of this programme, all Dutch hospitals have been advised to implement an RRS (VMS, 2008). The advice was to set up a system containing an afferent, efferent, and feedback limb and a general blueprint was given for the content of each limb. In addition, a generic roadmap for preparing for implementation was provided, which included inter alia the advice to set up an implementation team and define a plan for communication and training about the RRS. The generic roadmap did not however give advice on the steps to be taken during actual implementation or on the exact content of each limb.

To shed light upon the way in which the Dutch hospitals implemented their RRS, a qualitative study design was used. This study was part of an overall evaluation study of the complete Hospital Patient Safety Programme. For this overall study, 19 hospitals were randomly selected, stratified by location and teaching status (teaching: eight, non-teaching: 11). These hospitals were approached for an interview about RRS implementation. As one non-teaching hospital had not started its RRS implementation yet, 18 semi-structured interviews were conducted by trained interviewers. These were guided by a topic list based on available literature on the implementation of organisation-wide change (i.e., focus on innovation adoption and routinisation including the innovation content, process and context) (e.g., Pettigrew and Whipp, 1993; Greenhalgh et al., 2004) and RRS in particular (e.g., Jones et al., 2011). The topic list contained questions such as "What are the contents of the afferent, efferent and feedback limbs and how are they organized?", "How did you organize and address the implementation of the entire system?", "What factors concerning the hospital as a whole influenced the implementation?" etc.

In all hospitals, one interview was conducted. The contact person at each hospital was asked for the most appropriate person to interview, namely the one with the most knowledge or most closely involved with the RRS of the hospital. In ten hospitals the interview was conducted with the project leader for RRS implementation (mainly the ICU doctor) and in eight hospitals in combination with a second (and sometimes third) person involved in implementation (mainly an ICU nurse or quality officer). Data collection took place from December 2011 to May 2012. Table 1 shows an overview of the hospitals included in this research, stating some general characteristics for each (location, size, teaching status, etc.), the year in which the RRS was started and the number and type of interviewees.

The interviews were transcribed. Data was first analysed per hospital by means of thematic analysis. To explore approaches to RRS implementation, including the various stages of the implementation process, influencing factors and perceived effects of implementation, we followed a systematic data reduction process: reading of transcripts, codification of segments, generation of themes and categories, and identification of relationships (Miles and Huberman, 1994). Process descriptions were created for each hospital including both early and later stages of implementation and we created thematic conceptual matrices for factors perceived as helping and hindering during the adoption and routinisation phases. Common themes and working practices were identified from the within-case analyses, which led to the cross-case analysis providing insights into how (different types of) Dutch hospitals deal with RRS implementation. 
Table 1 Hospital characteristics and number (type) of interviewees

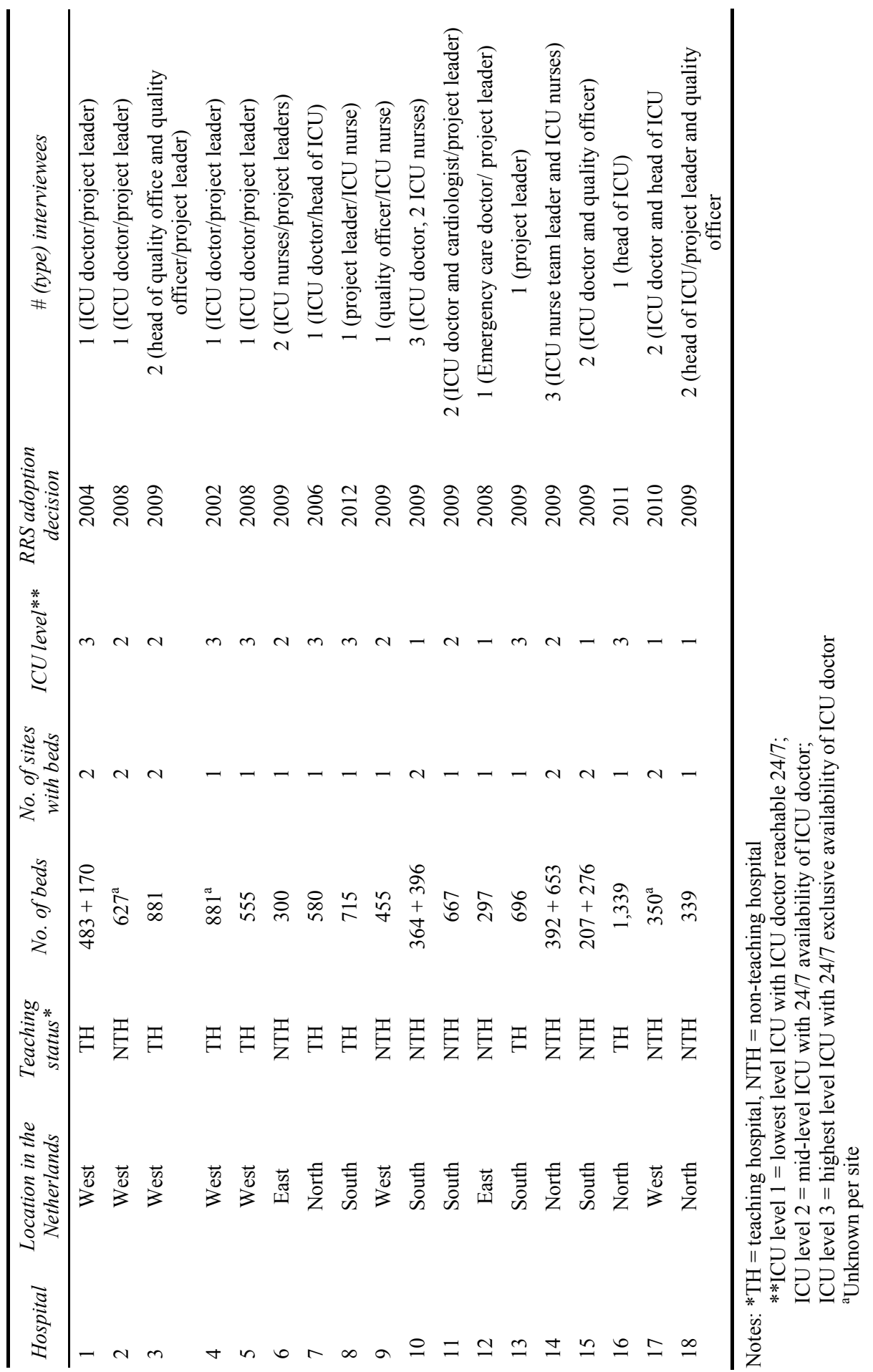




\section{Results}

The within-case analysis of each hospital, including implementation organisation, implementation process, the perceived promoting and hindering factors during adoption and routinisation and the perceived outcomes of the RRS, is summarised in Appendix A (hospitals are indicated by numbers 1 to 18 ). In this section, we present our cross-case findings. First, a description of the implementation process is provided. Thereafter, we shed light upon the contents of the implementation, the context of implementation and the relationships between these concepts. Where possible, we point out the relationship between hospital characteristics as described in Table 1 and the implementation approach chosen.

\subsection{The process of RRS implementation}

In the majority of the hospitals (12 out of 18), the ICU took the initiative/decision to set up the RRS. In the other six hospitals, the initiative/decision was taken by top management or the quality office. Four of these hospitals were non-teaching hospitals. In all hospitals, implementation was organised by assigning a team responsible for RRS implementation. In nine hospitals, this implementation team was composed entirely of professionals working at the ICU. In the other nine hospitals, the implementation team consisted of healthcare professionals working at different parts of the hospital. From the five hospitals with a small level 1 ICU (Table 1), four organised a hospital-wide implementation team. Table 2 shows a matrix with the decision making unit and accompanying implementation team organisation for each hospital. Interviewees in the hospitals with an ICU implementation team indicated that it was important that those with the most knowledge about a subject should be responsible for executing related tasks, in this case the implementation and setup of the RRS. In the hospitals with a hospital-wide implementation team, interviewees emphasised the importance of the scope of the improvement project; those who would be affected by the project should be involved in its execution. Because the RRS is capable of improving the entire hospital system, it could not be considered as 'just an ICU toy' (hospital 1) and professionals and managers representing various hospital entities had been involved to work together towards a safer hospital.

In each hospital, the implementation team implemented an RRS that contained an afferent limb (i.e., monitoring procedures to recognise deteriorating patients and criteria for calling the RRT), an efferent limb (i.e., the rapid response team including appropriate professionals and equipment) and a feedback limb (i.e., overall evaluation and analysis of calls with the aim of continuous improvement of the RRS) (Jones et al., 2011), as advised by the National Patient Safety Programme (VMS, 2008). During the implementation process, the implementation teams took various steps to finally implement the RRS. These steps are summarised in Table 3, which suggests that two approaches to RRS implementation can be discerned: a stepwise approach and a non-stepwise approach. In the five hospitals with the non-stepwise approach, the adoption phase consisted of the assignment of the implementation team. After that, the RRS was implemented on all hospital wards at once (after training the hospital personnel) to achieve routinisation. The hospitals that followed this approach were all non-teaching hospitals that considered themselves as small. They reasoned that the size of their hospital or respective sites made 
it possible to monitor and steer the implementation process quite easily without first having to pilot it.

Table 2 Initiative taken and implementation team composition

\begin{tabular}{lccc}
\hline & & \multicolumn{2}{c}{ Initiative taken by } \\
\cline { 3 - 4 } & & ICU & Top management/quality office \\
\hline Implementation & ICU only & $2,3,5,6,11,14$ & $9,10,13$ \\
team composition & Hospital-wide & $1,4,7,8,12,17$ & $15,16,18$ \\
\hline
\end{tabular}

Table 3 Steps in the implementation process

\begin{tabular}{|c|c|c|}
\hline Step in process & \multicolumn{2}{|c|}{ Hospitals } \\
\hline ADOPTION & Stepwise approach & Non-stepwise approach \\
\hline Decision making/initiative taking & \multicolumn{2}{|c|}{ All sites } \\
\hline Assignment of implementation team & \multicolumn{2}{|c|}{ All sites } \\
\hline Training of pilot wards & \multicolumn{2}{|c|}{$\begin{array}{c}1,2,3,4,5,6,7,8,9,10,13 \\
15,(16)\end{array}$} \\
\hline Pilot in one/small number of wards & \multicolumn{2}{|c|}{$\begin{array}{c}1,2,3,4,5,6,7,(8), 9,10,13 \\
(15),(16)\end{array}$} \\
\hline ROUTINISATION & Stepwise approach & Non-stepwise approach \\
\hline Training in all hospital wards & \multicolumn{2}{|c|}{ All sites (except hospital 9) } \\
\hline Implementation on all wards at once & \multirow{2}{*}{\multicolumn{2}{|c|}{$11,12,14,17,18$}} \\
\hline $\begin{array}{l}\text { Gradual implementation on trained } \\
\text { wards }\end{array}$ & & \\
\hline Afferent limb implemented & \multicolumn{2}{|c|}{$1,2,3,4,5,6,7,9,10,13$} \\
\hline Efferent limb implemented & \multicolumn{2}{|c|}{$1,2,3,4,5,6,7,9,10,13$} \\
\hline Feedback limb implemented & \multicolumn{2}{|l|}{$1,3,7,13$} \\
\hline Feedback limb under construction & \multicolumn{2}{|l|}{$2,5,6,9$} \\
\hline No feedback limb yet & \multicolumn{2}{|l|}{$4,10,15$} \\
\hline Not any limb yet & \multicolumn{2}{|l|}{8,16} \\
\hline $\begin{array}{l}\text { Looking for improvements/to-do's in } \\
\text { system }\end{array}$ & \multicolumn{2}{|c|}{ All sites } \\
\hline In afferent limb & \multicolumn{2}{|c|}{$1,2,3,4,7.9,11,12,13,14,18$} \\
\hline In efferent limb & \multicolumn{2}{|c|}{18} \\
\hline In feedback limb & \multicolumn{2}{|c|}{$4,5,6,9,10,15,17$} \\
\hline
\end{tabular}

Notes: No operational RRS: $8,15,16$

(n): action planned but not operationalised yet

The stepwise approach to implementation was followed by 13 project teams. This approach consisted of various steps in both the adoption and routinisation phase, starting with a pilot in one or a few wards during the adoption phase, followed by gradual unrolling of the RRS to achieve routinisation. In all but one (hospital 9) of these hospitals, training of hospital ward nurses and doctors was a prerequisite for the implementation of the RRS on a particular ward; the RRT and accompanying procedures were only operationalised on a ward when $60-100 \%$ of the medical staff had been trained in these procedures. 
In addition to focusing on one ward at a time, the stepwise approach also focused on one RRS limb at a time. All hospitals first focused on the implementation of the RRT and the early recognition procedures, i.e., the efferent and afferent limbs. In this way, the hospitals aimed to get the system up and running and provide hospital professionals with a means to provide better care to critically ill patients in hospital wards. The feedback component, required to complete the RRS and allow for continuous improvement, was implemented in a second stage, as can be seen in Table 4 where the rows on gradual implementation of the RRS on trained wards shows that many hospitals are lacking a (fully functioning) feedback limb. As one interviewee put it, "Once the team and accompanying procedures were more or less functioning, we developed further towards a rapid response system, including continuous training and evaluation" (hospital 3). In general, the setup of the RRT and introduction of the recognition procedure were perceived as relatively simple; interviewees indicated that hospitals had ample experience with implementing new procedures. Setting up a new care team had been experienced before. Implementation of the feedback limb, however, was perceived as far more complex. Because the feedback limb served to continuously improve the RRS and the hospital care system as a whole, interviewees felt that its implementation envisioned a large change encompassing the entire hospital at both the operational and managerial levels.

To routinise the RRS and embed its functioning, continuous training of ward personnel, analysis of RRT calls and structural feedback reports to wards and management were mentioned as primary points for improvement, along with improvements in the afferent limb. Hospitals that had already routinised the feedback limb mentioned different points for improvement, mainly focusing on further improvement of patient monitoring to aim for still earlier recognition of deterioration.

In summary, two different approaches were followed by hospitals in RRS implementation, a stepwise or a non-stepwise approach. Stepwise indicates that a distinction was made between various activities undertaken in the adoption and routinisation phase of implementation and also that the content of the RRS limbs was implemented one at a time.

\subsection{The content of RRS being implemented}

Even though each implementation team implemented an RRS consisting of an afferent, efferent and feedback limb, as advised by the National Patient Safety Programme, the content of the limbs appeared to differ among hospitals. Interviewees in 12 hospitals indicated that the content of the RRS had been adapted to the local situation. The afferent limb was adapted in eight hospitals, the efferent limb in seven and the feedback limb in three. Table 4 shows for each hospital what adaptations were made in which limb and why. From this table, it can be seen that there is a clear relationship between the limb being adapted and the reason given for this by the interviewees. Adaptations in the afferent limb were all related to professional and patient characteristics. Professional characteristics (e.g., existing knowledge on wards, division of tasks and responsibilities) influenced the type and number of triggers included in the early warning procedure, and the thresholds set within this early warning procedure. Patient characteristics, such as the risk of the patient deteriorating, influenced the way in which the early warning procedure was adapted to suit different wards. 
Table 4 Adaptations made to content of the RRS

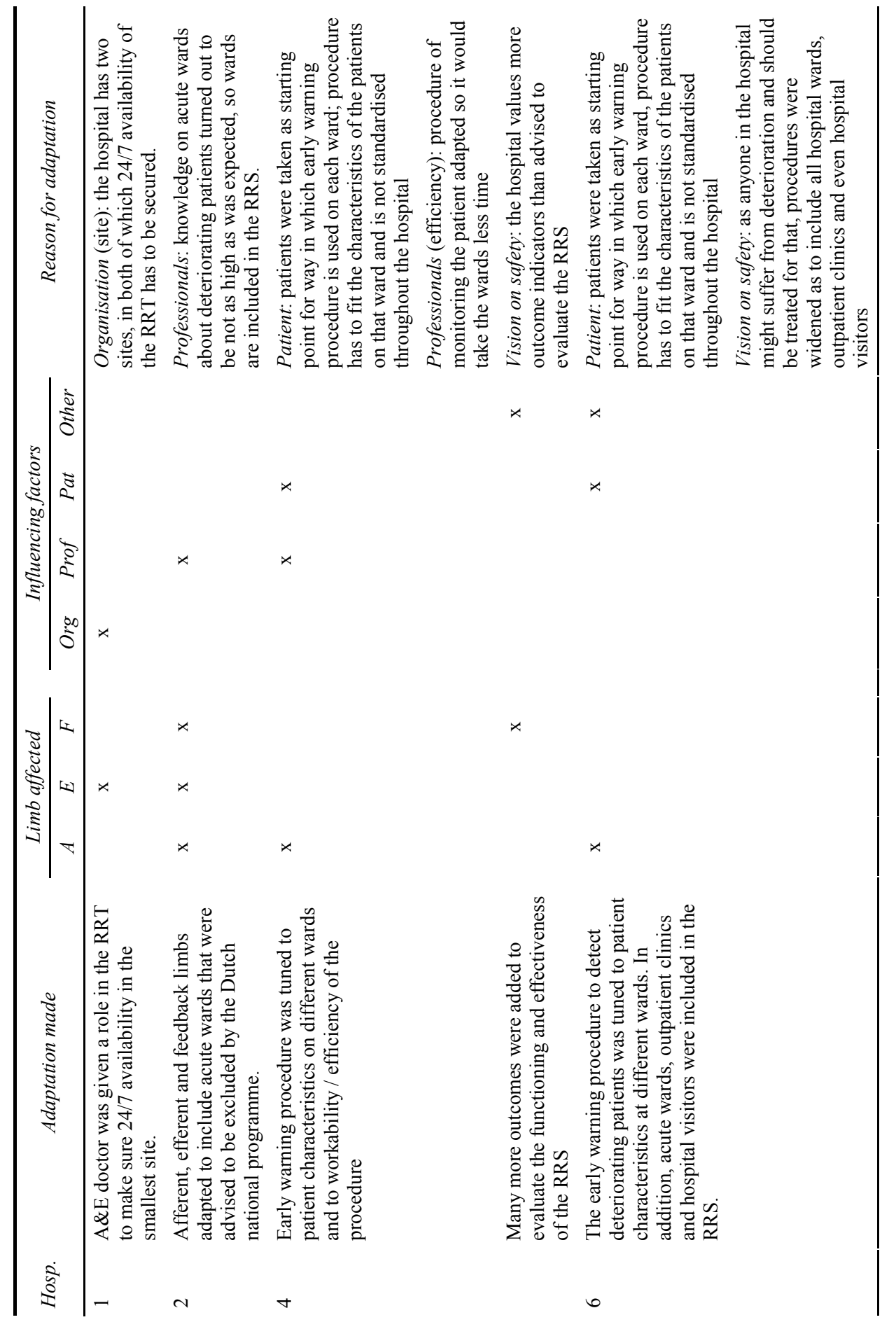


Table 4 Adaptations made to content of the RRS (continued)

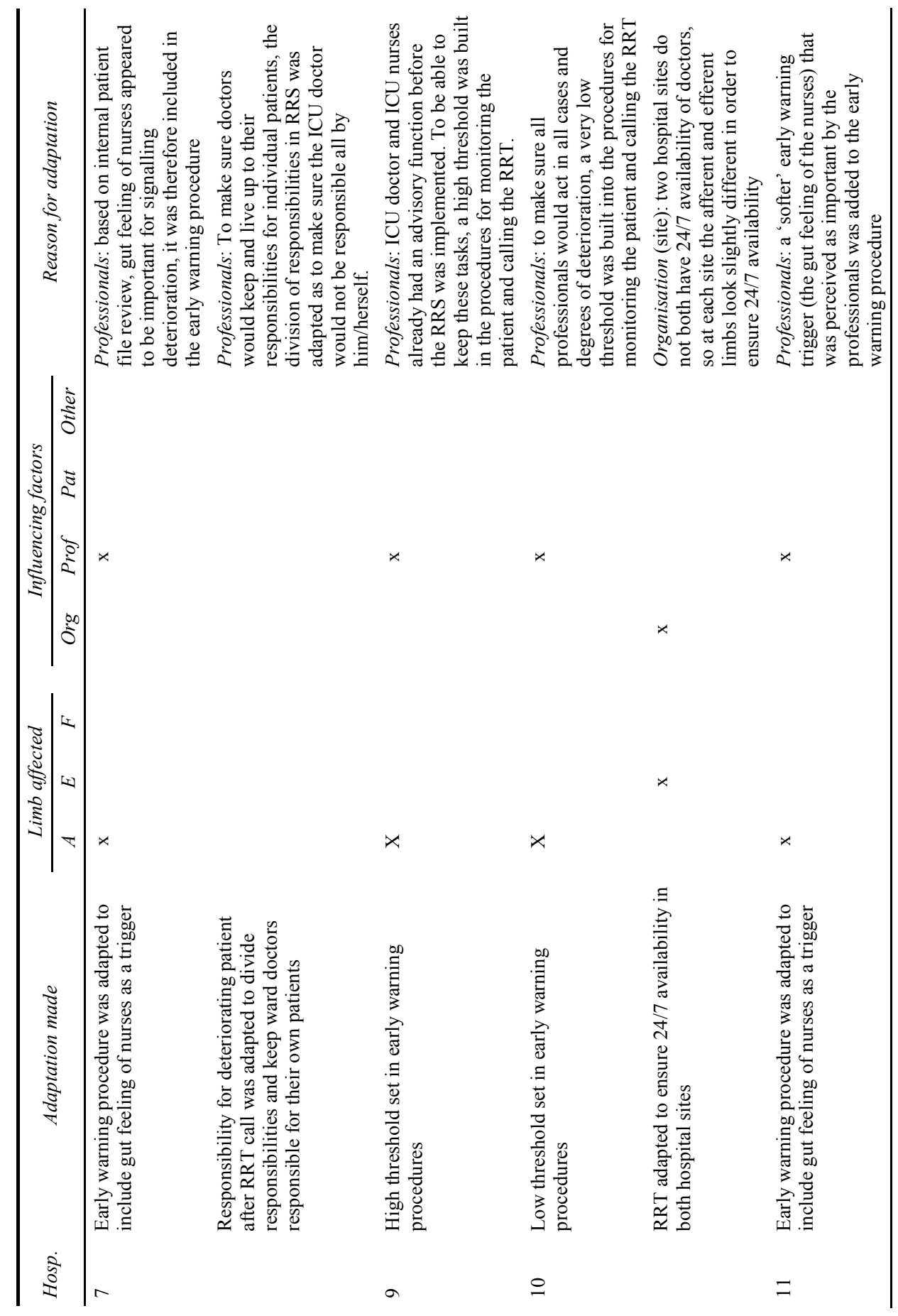


Table 4 Adaptations made to content of the RRS (continued)

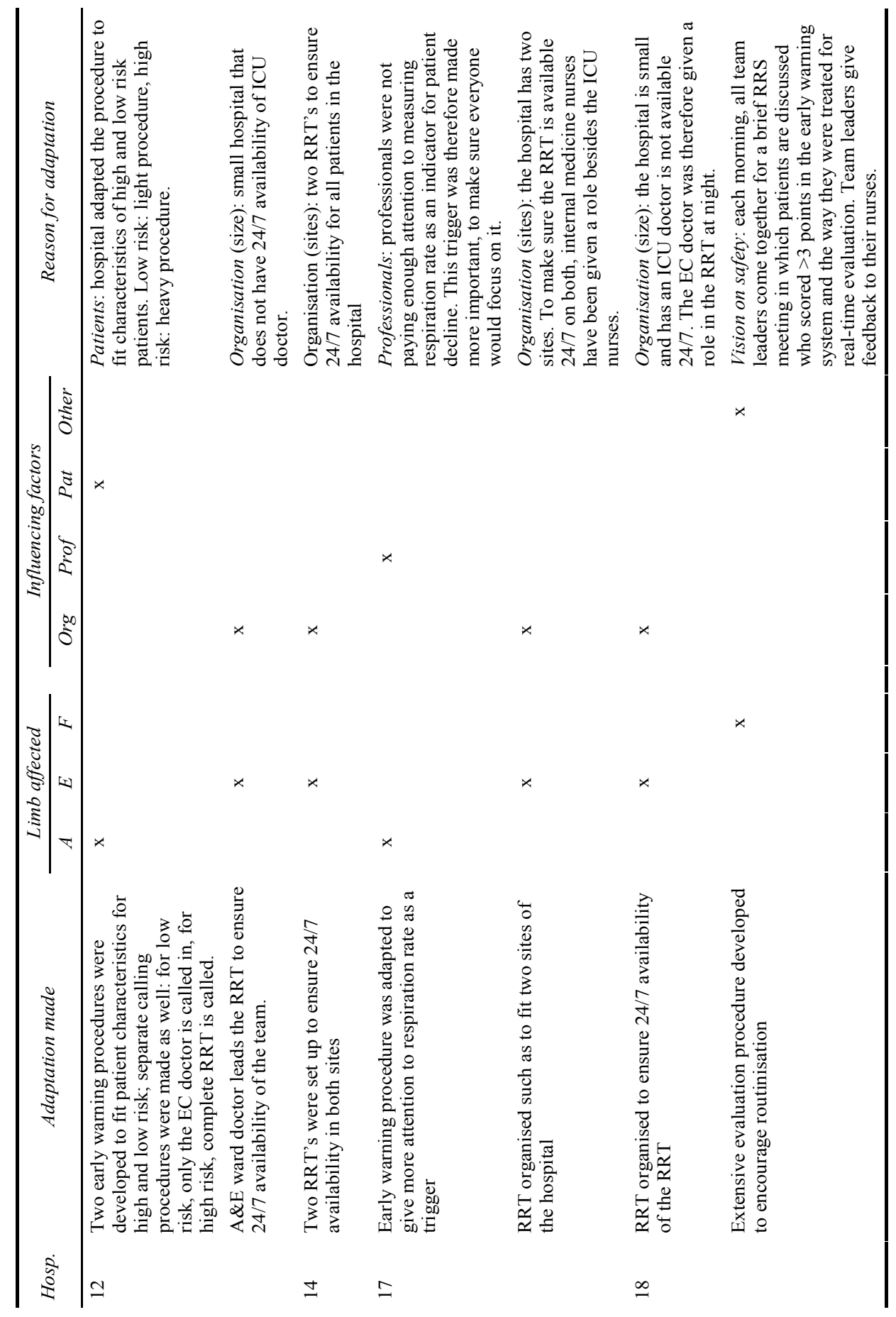


Adaptations to the efferent limb were all related to organisational characteristics (hospital size, number of sites). Small hospitals in particular adapted the composition of the RRT to ensure 24/7 availability. Hospitals with more than one site set up a second rapid response team (often including an emergency care doctor instead of an ICU doctor) to make sure all patients could be taken care of.

A fourth influencing characteristic was identified, namely the way in which the hospital as a whole looked upon safety issues and aimed to organise its processes and procedures around that. This influenced the outcome measures taken into account or the way in which evaluations were conducted. In one hospital, its vision on safety influenced its afferent procedure to include not only patients but all people present in the hospital, including professionals and visitors.

Of the hospitals that had not made any adaptations (as yet), three $(8,15,16)$ had an RRS that was currently not operational. Because the RRS was designed only on paper, these hospitals had not been able to experience its functioning. The RRS of one of the other three hospitals that did not make any adaptations $(3,5,13)$ was taken as the example by the Dutch Hospital Patient Safety Programme. The blueprint of the RRS that was advised to all Dutch hospitals was based on this RRS.

In summary, we identified factors related to the hospital organisation, to professionals, patients and to the safety vision as influencing the adaptation of the efferent, afferent and feedback limbs. Different types of contextual factors therefore appear to influence what parts of the RRS content were adapted and how.

\subsection{Influencing factors in the implementation context}

In addition to the effect of the context on content, we aim to shed light upon context-related factors and their influence on the process of RRS implementation. The interviewees all mentioned various factors that were helping or hindering the implementation of the RRS either in the adoption or routinisation phase (see Appendix A).

Context factors were divided into the categories of hospital organisation, professionals, patients and safety view, since these categories were shown to be relevant in the previous section. No promoting or hindering factors appeared to be related to patients or safety view. However, a different category, both promoting and hindering implementation, was identified, being the organisation of the implementation project for RRS implementation. Figure 2 shows what type of contextual factors were perceived as helping $(+)$ or hindering $(-)$ by what number of hospitals in what phase of the implementation process (adoption versus routinisation). Appendix B gives detailed information on the promoting and hindering factors and by how many hospitals they were perceived.

Overall, hospital organisational factors and professional factors were more often perceived as hindering than helping, both in the adoption and in the routinisation phase. Factors related to the organisation of the implementation project were more often perceived as promoting than as hindering, both in the adoption and in the routinisation phase. In addition, the interviewees mentioned more factors affecting the adoption phase than the routinisation phase. This might also be due to the rather early stage of implementation that most of the hospitals were still in. 
Figure 2 Promoting and hindering factors in RRS implementation (see online version for colours)

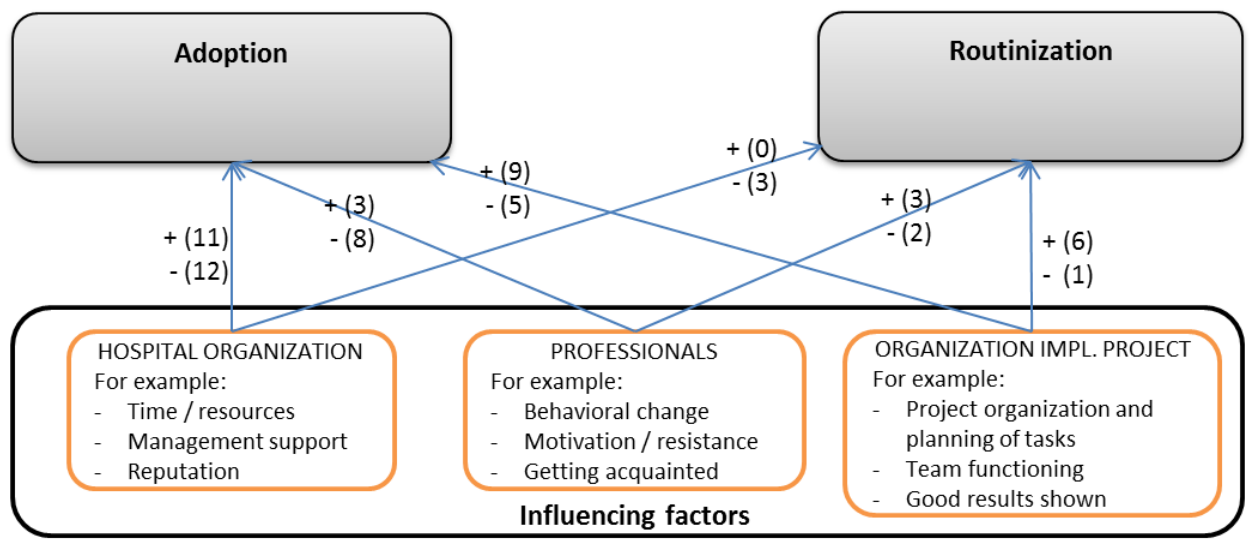

Notes: $+(\mathrm{n})=$ number of hospitals perceiving facilitating factor in this category.

$-(\mathrm{n})=$ number of hospitals perceiving hindering factor in this category.

The adoption phase was mostly affected by hospital organisational factors. Among others, these included the size of the hospital, availability of time and resources, and management support. In 12 hospitals, these had been perceived as hindering; the most prevailing hindering factor was perceived lack of time and/or resources (seven hospitals). Interviewees from 11 hospitals mentioned the adoption phase had been facilitated by factor related to the hospital organisation. The most prevailing facilitating factor was support from the hospital board (eight hospitals), followed by ICU reputation and availability of time and resources (both three hospitals). Eight hospitals perceived one or more factors related to professionals as hindering the adoption phase, such as resistance among doctors (eight hospitals), and the behavioural changes required (three hospitals). Three hospitals perceived professionally related factors as a help during RRS adoption; all three mentioned motivation of professionals on hospital wards as facilitating change. Factors related to the organisation of the implementation project were perceived as hindering RRS adoption by five hospitals and helping it by nine. Hindering factors concerned, e.g., having no formal project organisation or delays because of too many discussions and meetings with wards. Examples of promoting factors were an inspiring/motivating implementation team (four hospitals), a hospital-wide implementation team, or commitment created by meetings with wards (both two hospitals).

With respect to routinisation, three hospitals perceived hospital organisational factors as hindering (mainly lack of time and resources), none perceived these factors as promoting, two perceived professionally related factors as hindering (behavioural change required), and three perceived professional related factors as facilitating (professionals getting used to the system). Factors related to the organisation of the project were perceived as facilitating in six hospitals and hindering in one, which lacked a formal project organisation. The most important facilitating factor was communication of good evaluations and results of the adoption phase (five hospitals, four of them teaching hospitals). The outcomes of measurements made during the pilot and early implementation phase motivated nurses and convinced doctors of the value of the RRS which promoted routinisation. 
Availability of resources is mentioned in literature as influencing both adoption and routinisation of any innovation (Greenhalgh et al., 2004; Klein and Knight, 2005; Simpson and Flynn, 2008). Availability of resources was mentioned in seven hospitals as a hindrance and in three hospitals as a help to RRS implementation. Table 5 shows the availability of resources per hospital and per limb. In teaching hospitals, resources were often made available for the evaluation limb (hospitals 1, 3, 4, 7, 13) and for training (hospitals $4,5,7,8,13$ ) in terms of time, money and back-office support. In non-teaching hospitals, if resources were made available, this was mainly for the efferent component to make sure that the RRT was able to come with personnel and equipment when a call was made $(2,6,10,14)$. Except for hospital 16, the hospitals where no resources were made available were all non-teaching hospitals.

Table 5 Availability of resources per limb

\begin{tabular}{lc}
\hline Part of RRS & Hospitals \\
\hline Afferent & $4,5,7,8,11,13,18$ \\
Efferent & $2,4,6,10,11,13,14$ \\
Feedback & $1,3,4,7,11,13$ \\
None & $9,12,15,16,17$ \\
\hline
\end{tabular}

\subsection{Perceived effects of the RRS}

A summary of the perceived effects of RRS implementation for all hospitals is given in Table 6. The effect perceived most often was the value of the RRS to nurses. Twelve interviewees described how the fact that the afferent component includes procedures for measure a patient's vital signs made nurses feel more empowered, as the measurements gave them a means of confirming their feeling that the patient was deteriorating. "Nurses now have a tool available that lets them make their gut feeling concrete" (hospital 15). Five interviewees pointed out that better communication between nurses and doctors resulted from these procedures, because nurses informed doctors about the patient's situation for each vital sign measured, thereby communicating in a more standardised way. "The measures made available by the scoring system help them [the nurses] communicate on an equal level with the doctor" (hospital 4). Better communication, learning opportunities, and likely reduction of CPRs were all perceived by hospitals with only one site. One hospital perceived a negative effect, namely that nurses felt intimidated sometimes by the RRT when they took over the deteriorating patient.

With respect to outcome measures, interviewees indicated that they experienced more RRT calls over time (a sign of better embedding in the system). One hospital (2) had fewer RRT calls over time; however the initiating doctor was consulted personally more often. Also, interviewees indicated fewer CPRs and shorter ICU stays because deteriorating patients were recognised earlier and action was taken earlier. It should be noted that the outcomes in most hospitals were based mostly on feelings; the numbers of RRT calls and the period over which it had been operational were too low/short to produce statistically significant results. 
Table 6 Perceived effects of the RRS being implemented

\begin{tabular}{lc}
\hline \multicolumn{2}{c}{ Perceived effects-descriptive } \\
\hline Nurses feel empowered & $1,3,4,5,6,7,9,10,11,14,15,17$ \\
Better doctor-nurse communication & $4,5,6,7,9$ \\
Likely reduction of CPRs & $4,6,7,9$ \\
Training and learning possibilities for nurses & $7,9,12$ \\
Patients get to ICU earlier & 14 \\
Nurses feel intimidated & 18 \\
\hline & Perceived effects - numerical \\
\hline More (fewer) RRT calls & $1,(2), 4,5,9$ \\
Fewer CPRs & $1,3,10$ \\
Shorter ICU stays & 7 \\
\hline
\end{tabular}

In summary, this section provided detailed insights into the process, content and context of RRS implementation. In addition, the interviews revealed interrelationships between process, content and context of RRS implementation. After the decision to adopt the RRS, two types of implementation processes were identified, stepwise and non-stepwise. The second of these was mainly followed by small hospitals. Content of the RRS influenced the stepwise implementation process, providing the order in which parts of the RRS were implemented. In addition, content of the RRS was adapted for various factors related to the hospital context. More specifically, which components of the RRS content were adapted (efferent, afferent or feedback) was directly related to contextual factors concerning the organisation, professionals, patients and vision on safety respectively. The context also influenced the implementation process. Contextual factors related to hospital organisation and professionals were mainly perceived as hindering, whereas factors related to the organisation of the implementation project were more often perceived as facilitating the adoption and routinisation of RRS implementation.

Based on our findings, we adapted and tuned the framework for innovation implementation, as developed in the theoretical section of this paper (see Figure 1), to a framework reflecting RRS implementation (see Figure 3). In essence, Figure 3 shows the relationships between innovation content, innovation context and the process of implementation that were experienced by the hospitals in our study. Various factors that were related to the innovation context can influence the process of RRS implementation as well as the adaptations made to the RSS content. The content itself influences the implementation process, but only the stepwise version. The greater emphasis on the fact that innovation content and innovation context are not independent concepts influencing the process of implementation, means that the adapted framework reflects the complex reality of innovation implementation better. 
Figure 3 Framework for RRS implementation

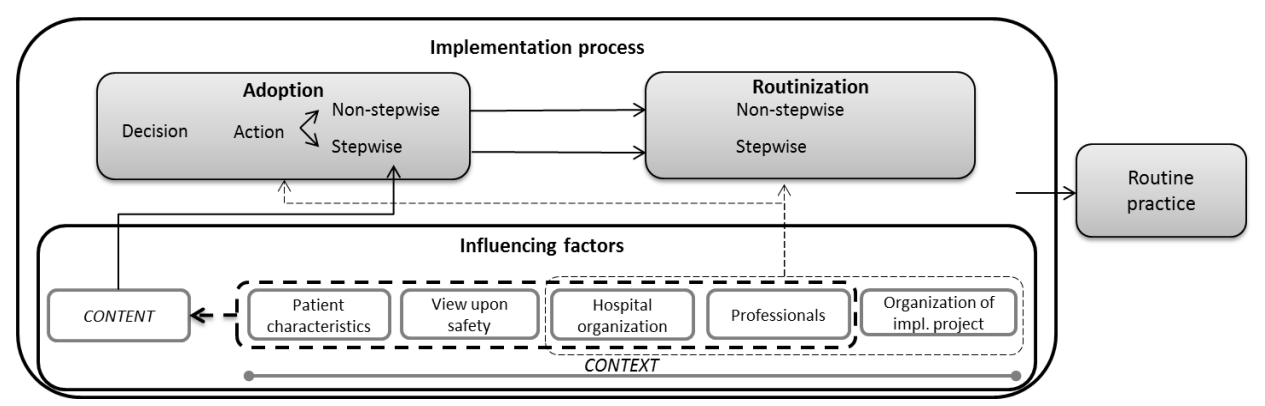

\section{Discussion and conclusions}

This paper aimed to provide insights into how hospitals implement their RRS and how the approach chosen is determined. The implementation process is seen as the key stage between the decision to adopt an innovation and its routine use in practice (Klein and Knight, 2005; Klein and Sorra, 1996). However, there are currently no in-depth insights into this process (Fixsen et al., 2005; Simpson and Flynn, 2008). Gaining meaningful insights into the implementation process and offering practical guidance to hospitals would not have been possible if we examined the innovation process in isolation. In this study, the innovation content, implementation context and implementation process (Pettigrew and Whipp, 1993) were studied together through semi-structured interviews. This approach provided insights that go well beyond the experiences of single organisations, which are what have mainly been presented in the literature so far (DeVita and Hillman, 2011). It adds both breadth and depth to current literature. The approaches taken by 18 hospitals revealed great diversity in implementation processes, contents and contexts. At the same time, we were able to zoom in on these three elements, thereby revealing relationships between them. Previous research has presented the content and context as independent concepts that both influence the process of implementation [see Figure 1, representing the view of Klein et al. (2001; Klein and Knight, 2005; Klein and Sorra, 1996), Simpson and Flynn (2008)]. Our study has shown that these concepts are interrelated, in the sense that the implementation's context also influences the content of the innovation being implemented. Additionally, we were able to distinguish various types of contextual factors that influence either the implementation process, the innovation content, or both. This study adds depth to insights into implementation of innovations in healthcare contexts. The framework developed points out the relationships between content, context and the process of implementation. It can be used as a starting point for future research focusing on greater understanding of these relationships and working towards a theory for the implementation of system-wide innovations in healthcare settings and elsewhere.

As for innovations in general, the implementation process for an RRS consists of two stages, adoption and routinisation (e.g., Klein and Sorra, 1996; Greenhalgh et al., 2004; Simpson and Flynn, 2008). Within those stages, our data revealed two approaches for designing the implementation process. The non-stepwise approach was followed only by smaller, non-teaching hospitals. The stepwise process was followed by all hospital types 
and focused on ward-by-ward implementation as well as limb-by-limb implementation of the RRS. Implementation of the feedback limb was seen as far more difficult or radical than the afferent and efferent limbs; implementation approaches were adjusted accordingly. Previous research into innovation implementation has identified that an innovation can be incremental or radical and that the implementation process chosen should be contingent upon how the innovation is characterised by its users (Rogers, 1995). Our study implies that an innovation (the RSS) can not only be categorised as incremental or radical as a whole, but also that elements within it can be seen by the organisation as either incremental (the afferent and efferent limb) or radical (the feedback limb). This might have motivated many of the hospitals to split the simpler (incremental) changes from the more complex (radical) ones during implementation, thus resulting in a stepwise implementation process.

The content of the RRS was adapted or 'localised' in two-thirds of the hospitals. This finding is in accordance with Greenhalgh et al. (2004) and Simpson and Flynn (2008), who state that many innovations, require adapting to the local situation. However, those studies do not go into the reasons for adapting an innovation. Our study found that contextual factors related to the organisation, professionals, patients and safety provided grounds for content adaptation. Moreover, direct relationships appeared between the contextual reasons provided and the parts of the content adapted (with the efferent limb adapted for organisational factors, the afferent limb for professional and patient-related factors and the feedback limb for factors related to views on safety).

When abstracting these insights towards a broader perspective on the localisation of innovations, this might imply that the core of an innovation (here, the RRT or efferent limb) would most likely be adapted to comparatively fixed parameters of the organisation in which the innovation is being implemented (size, site, resources). The procedures and working instructions of how to deal with the innovation core (here, the afferent limb or early recognition procedures) will mainly be adapted for those who are affected by the innovation, in this case both professionals and patients. The fit between the innovation and the organisational system as a whole seems to be affected by relatively intangible concepts such as vision, culture or climate. These ideas provide an interesting starting point for future research into the adaptation or localisation of innovation content. They should be examined in more detail both within healthcare and elsewhere.

As explained above, contextual factors influence innovation content as well as the innovation process. Some of the factors facilitating or hindering the process of RRS implementation are in accordance with the findings of other authors (Greenhalgh et al., 2004; Simpson and Flynn, 2008). These mainly concerned organisational and staffrelated factors. In addition, this study revealed that the setup of the innovation project has a major influence on the process, mainly in terms of facilitating it, whereas organisational and staff-related factors were more often perceived as hindrances.

One context-related factor that has already received attention in the literature on RRS implementation is the type of hospital (teaching or non-teaching). Jones and Bellomo (2011) put forward the idea that non-teaching hospitals might set up simpler structures for implementing the RRS because of their limited resources and lower-risk patients. The non-teaching hospitals included in our study, however, tended to design more complex structures for the efferent limb (the RRT) in order to ensure 24/7 availability of the team. They therefore adapted the content of the RRS to work towards the aim of having the RRS available for all patients around the clock and did not take their limited hospital resources as starting point. 
The aim of this study was to relate hospital characteristics to the implementation approaches chosen. We were however unable to derive a clear pattern from the interviews. This implies that innovation implementation processes were largely customised in each hospital to suit the content, context and process factors at stake in that particular situation. Some points that our study did reveal were that the management tends to take the decision to adopt in non-teaching hospitals, with a non-stepwise process most likely to be chosen for the implementation; that hospitals with a small ICU tend to put together a hospital-wide implementation team; that small hospitals tend to adapt the efferent limb of the RRS more often; and that teaching hospitals tend to measure and use the outcomes of the adaptation phase more often in order to facilitate the routinisation phase of the implementation. Studies based on quantitative designs might in future provide more insights into relationships between hospital characteristics (or combinations thereof) and the approaches to innovation implementation.

Further opportunities for future research would lie in a more detailed study of the benefits or effects of the RRS. Existing studies have not shown consistent results in that regard (Chan et al., 2008) and many hospitals in this study were only able to describe the perceived effects. Quantifying the effects would also allow cost-benefit analysis that could be based on the cost calculations made by Edelson and Bellomo (2011). In addition, future research might focus on benefits perceived by the implementation team versus benefits perceived by professionals on the wards who were not part of the implementation team. For the purposes of this study, we chose to interview only people who were closely involved in RRS implementation. However, as all hospital staffs are involved in the routinisation of the RRS, it will be useful to broaden the research scope.

RRSs are being introduced in many countries (Jones et al., 2011). Based on our findings, we would advise hospitals to follow general guidance on RRS content, but adapt it to fit the local hospital setting. With respect to the implementation process, a stepwise process helps separate the more incremental changes from more radical changes in the organisation and makes the implementation easier to handle. However, for smaller hospitals, it might save time and resources to implement the RRS in the whole hospital at once. For people studying organisational design and engineering, our research provides insights in greater depth and examples that can be used for more efficient and effective implementation of quality-related concepts. We hope that this paper will provide a starting point for future research into system improvements in the healthcare sector.

\section{Acknowledgements}

The authors would like to thank Karien Hammink for her contribution to our data collection.

\section{References}

Casalino, L.P., Devers, K.J. and Brewster, L.R. (2003) 'Focused factories? Physician-owned specialty facilities', Health Affairs, Vol. 22, No. 6, pp.56-67.

Chan, P.S., Jain, R., Nallmothu, B.K., Berg, R.A. and Sasson, C. (2010) 'Rapid response teams: a systematic review and meta-analysis', Archives of Internal Medicine, Vol. 170, No. 1, pp.18-26. 
Chan, P.S., Khalid, A. and Longmore, L.S. et al. (2008) 'Hospital wide code rates and mortality before and after implementation of a rapid response team', Journal of the American Medical Association, Vol. 300, No. 21, pp.2506-2513.

DeVita, M.A. and Hillman, K. (2011) 'Barriers to the implementation of RRS', in DeVita, M., Hillman, K. and Bellomo, R. (Eds.): Textbook of Rapid Response Systems, pp.163-175, Springer: New York.

DeVita, M.A., Schaefer, J., Lutz, J., Wang, H. and Dongilli, T. (2005) 'Improving medical emergency team (MET) performance using a novel curriculum and a computerized human patient simulator', Quality and Safety in Health Care, Vol. 14, No. 5, pp.326-331.

Dutch Hospital Data (2012) Kengetallen Nederlandse Ziekenhuizen 2010 (English: Key Figures for Dutch Hospitals), DHD, Utrecht.

Edelson, D. and Bellomo, R. (2011) 'The costs and the savings', in DeVita, M., Hillman, K. and Bellomo, R. (Eds.): Textbook of Rapid Response Systems, pp.415-428.

Fixsen, D.L., Naoom, S.F., Blase, K.A., Friedman, R.M. and Wallace, F. (2005) Implementation Research: A Synthesis of the Literature, University of South Florida, No. Louis de la Parte Florida Mental Health Publication \#231, Tampa.

Garcia, R. and Calantone, R. (2002) 'A critical look at technological innovation typology and innovativeness terminology: a literature review', The Journal of Product Innovation Management, Vol. 19, No. 2, pp.110-132.

Greenhalgh, T. and Robert, G. et al. (2004) 'Diffusion of innovations in service organizations', Milbank Quarterly, Vol. 82, No. 4, pp.581-629.

Gregori, D., Napolitano, G., Scarzini, C., Semeraro, A., Rosato, R., Pagano, E., Zigon, G. and Gabassi, P. (2009) 'Knowledge, practise and faith on total quality management principles among workers in the health care system: evidence from an Italian investigation', Journal of Evaluation in Clinical Practice, Vol. 15, No. 1, pp.69-75.

Hansen, M.T. and Birkinshaw, J. (2007) 'The innovation value chain', Harvard Business Review, June, Vol. 85, No. 6, pp.121-130.

Hyer, N.L., Wemmerlov, U. and Morris, J.A. (2009) 'Performance analysis of a focused hospital unit: the case of an integrated trauma center', Journal of Operations Management, Vol. 27, No. 3, pp.203-219.

Jones D.A., DeVita, M.D. and Bellomo, R. (2011) 'Rapid-response teams', New England Journal of Medicine, Vol. 165, No. 2, pp.139-146.

Jones, D.A. and Bellomo, R. (2011) 'Impact of hospital size and location on feasibility of RRS', in DeVita, M., Hillman, K. and Bellomo, R. (Eds.): Textbook of Rapid Response Systems, pp.153-162, Springer: New York.

Jones, D.A., Bellomo, R. and DeVita, M.A. (2009) 'Effectiveness of the medical emergency team: the importance of dose', Critical Care, Vol. 13, No. 5, pp.313-317.

Klein, K. and Knight, A. (2005) 'Innovation implementation', Current Directions in Psychological Science, Vol. 14, No. 2, pp.243-246.

Klein, K. and Sorra, J. (1996) 'The challenge of innovation implementation', Academy of Management Review, Vol. 21, No. 4, pp.1055-1080.

Klein, K.J., Conn, A.B. and Sorra, J.S. (2001) 'Implementing computerized technology: an organizational analysis', Journal of Applied Psychology, Vol. 86, No. 1, pp.811-824.

Miles, M. and Huberman, A. (1994) Qualitative Data Analysis, Sage Publications: Thousand Oaks.

Morton, A. and Cornwell, J. (2009) 'What's the difference between a hospital and a bottling factory?', British Medical Journal, Vol. 339, No. b2727, pp.428-430.

Øvretveit, J. (2000) 'Total quality management in European healthcare', International Journal of Health Care Quality Assurance, Vol. 13, No. 2, pp.74-79.

Pettigrew, A. and Whipp, R. (1993) Managing Change for Competitive Success, Blackwell Publishers: Oxford.

Rogers, E. (1995) Diffusion of Innovations, Free Press, New York. 
Shortell, S.M., Jones, R.H., Rademaker, A.W., Gillies, R.R., Dranove, D.S., Hughes, E.F.X., Budetti, P.P., Reynolds, K.S.E. and Huang, C. (2000) 'Assessing the impact of total quality management and organizational culture on multiple outcomes of care for coronary artery bypass graft surgery patients', Medical Care, Vol. 28, No. 2, pp.207-217.

Simpson, D.D. and Flynn, P.M. (2008) 'Moving innovations into treatment: a stage-based approach to program change', Journal of Substance Abuse Treatment, Vol. 33, No. 2, pp.111-120.

VMS (2008) Vroege herkenning en behandeling van de vitaal bedreigde patiënt (English: Early Recognition and Treatment of Deteriorating Patients), VMS, Utrecht, the Netherlands.

Walley, P. (2003) 'Designing the accident and emergency system: lessons from manufacturing', Emergency Medicine Journal, Vol. 20, No. 2, pp.126-130.

Winters, B.D., Pham, J.C., Hunt, E.A., Guallar, E., Berenholtz, S. and Pronovost, P.J. (2007) 'Rapid response systems: a systematic review', Critical Care Medicine, Vol. 35, No. 5, pp.1238-1243. 


\section{Appendix A}

Table A1 Within-case analysis of RRS implementation

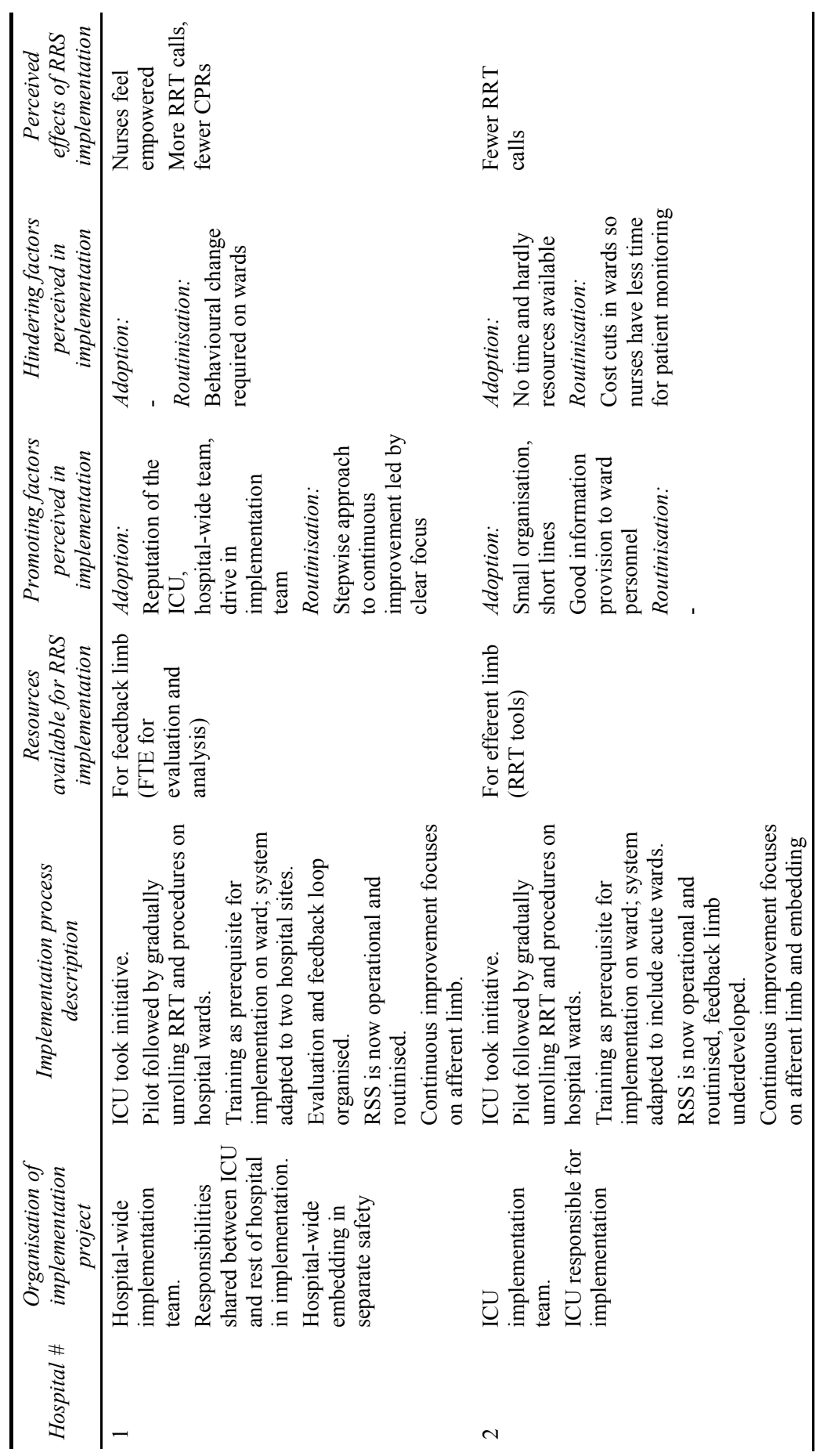


Table A1 Within-case analysis of RRS implementation (continued)

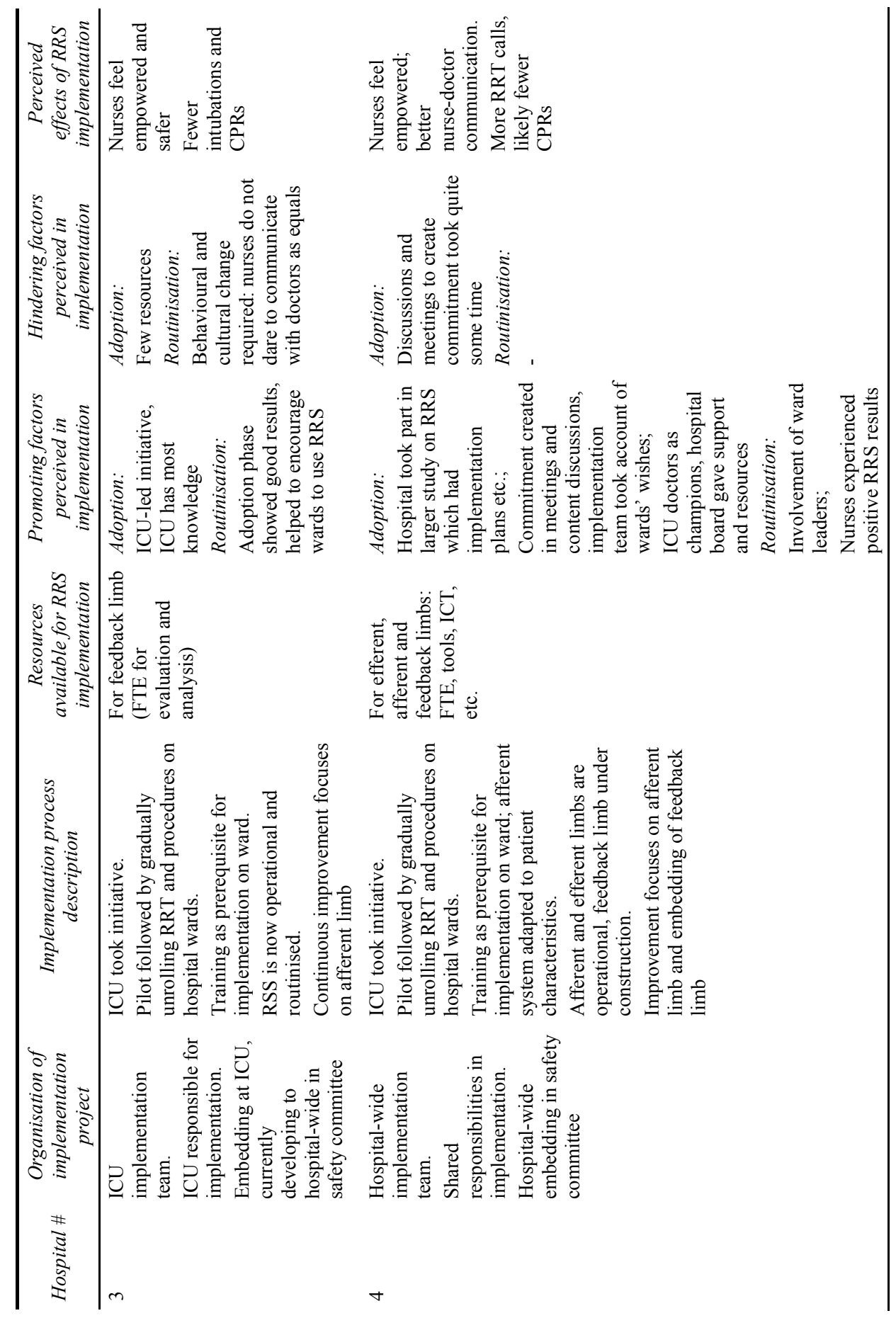


Table A1 Within-case analysis of RRS implementation (continued)

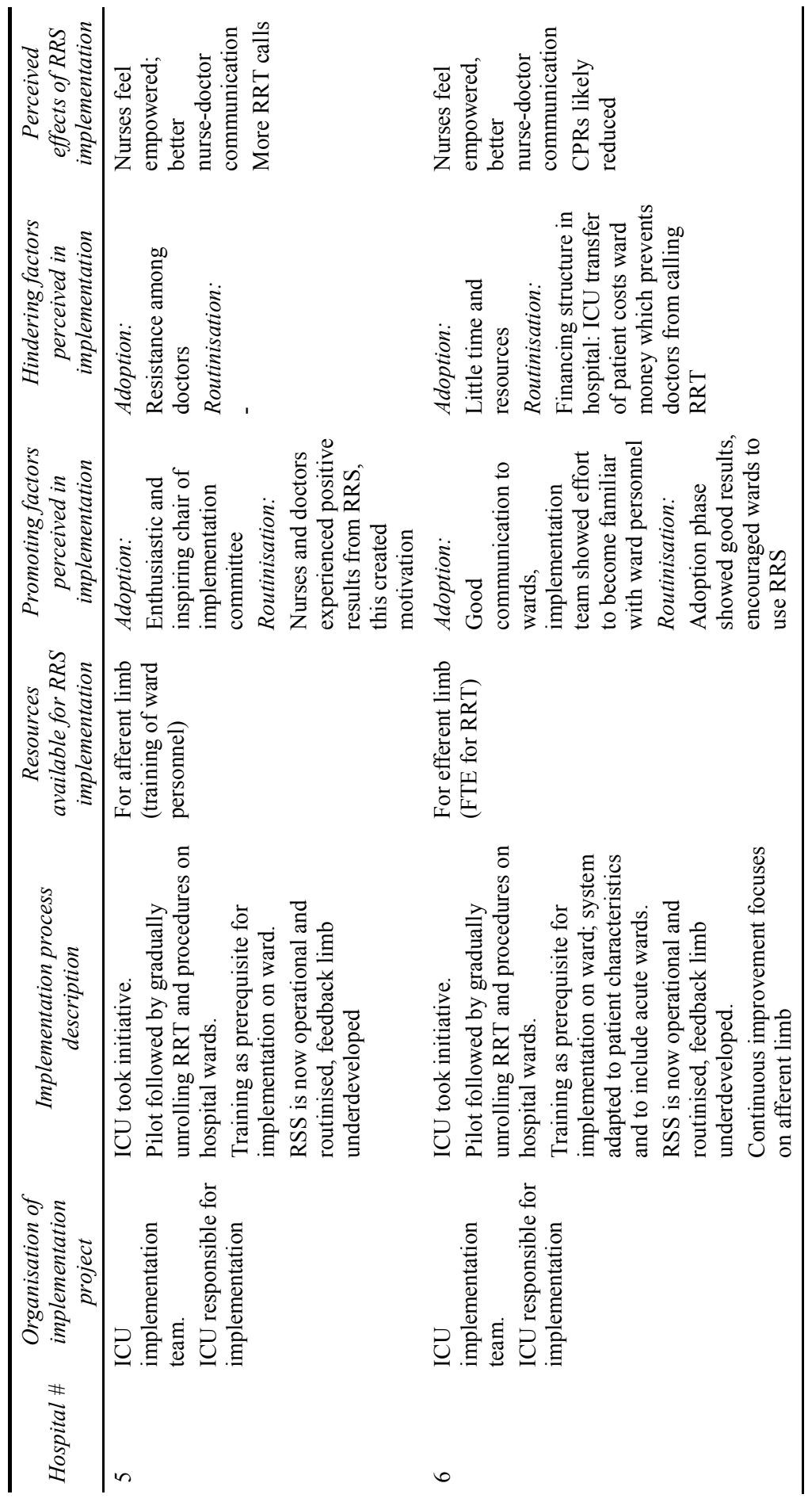


Table A1 Within-case analysis of RRS implementation (continued)

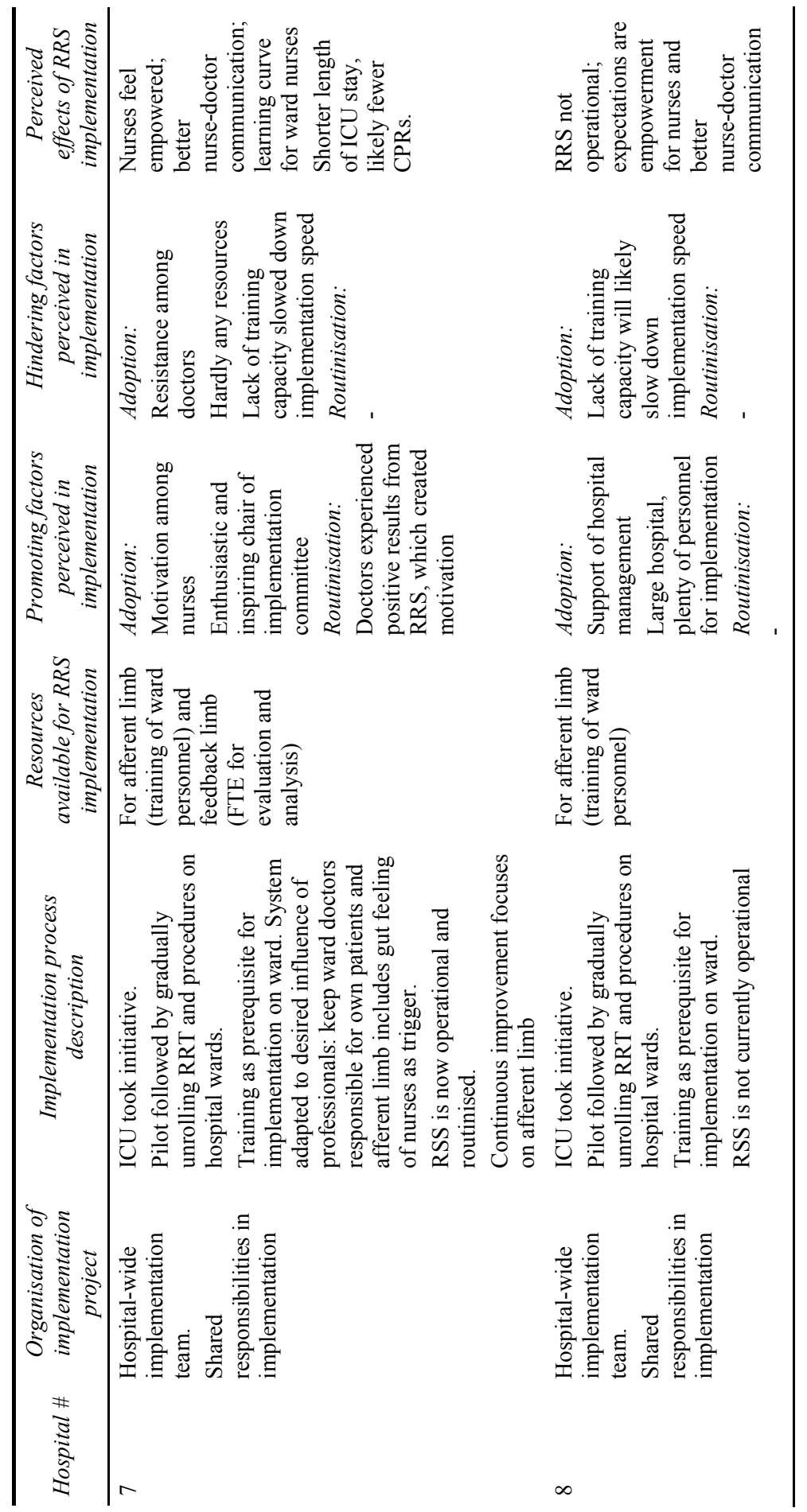


Table A1 Within-case analysis of RRS implementation (continued)

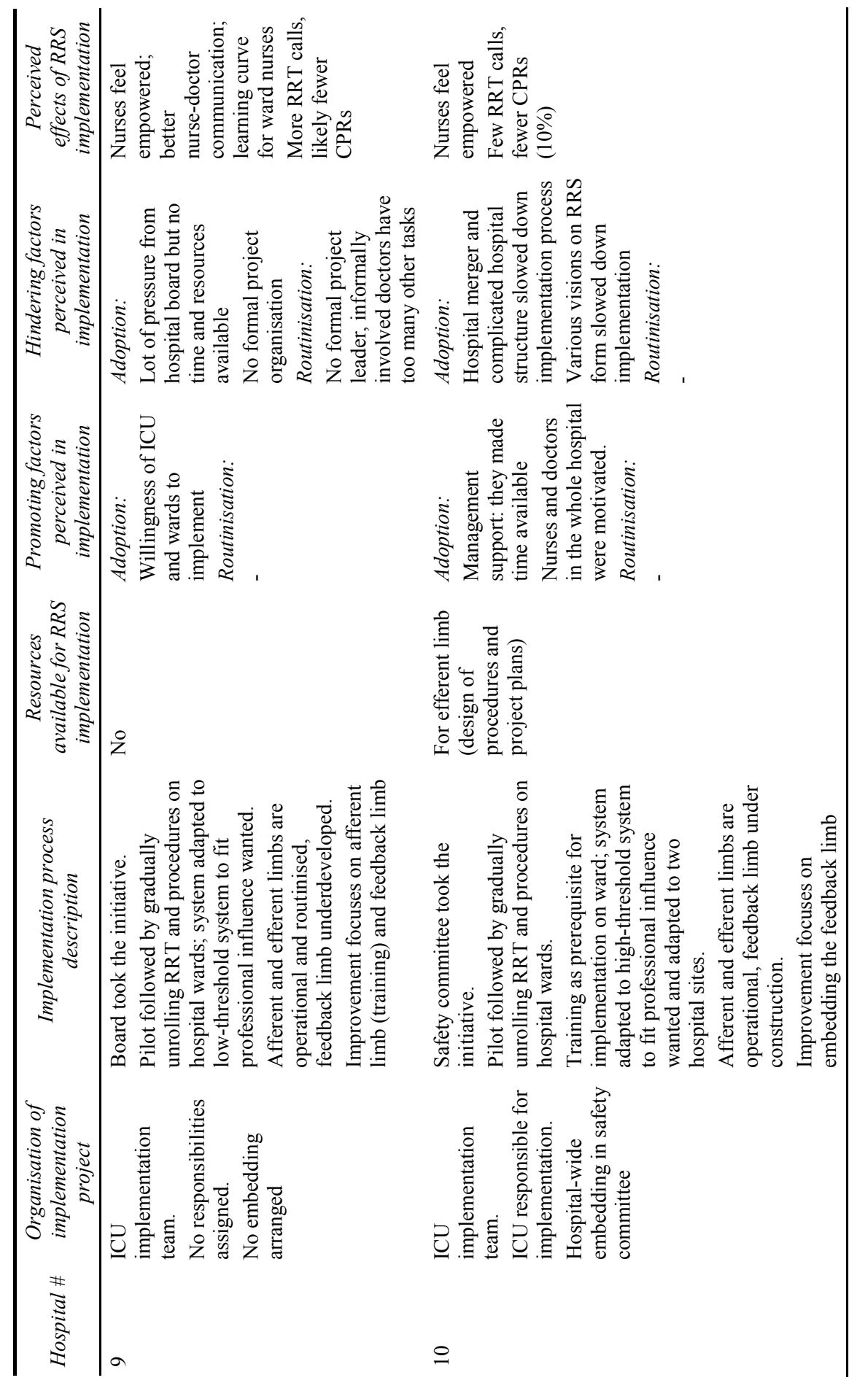


Table A1 Within-case analysis of RRS implementation (continued)

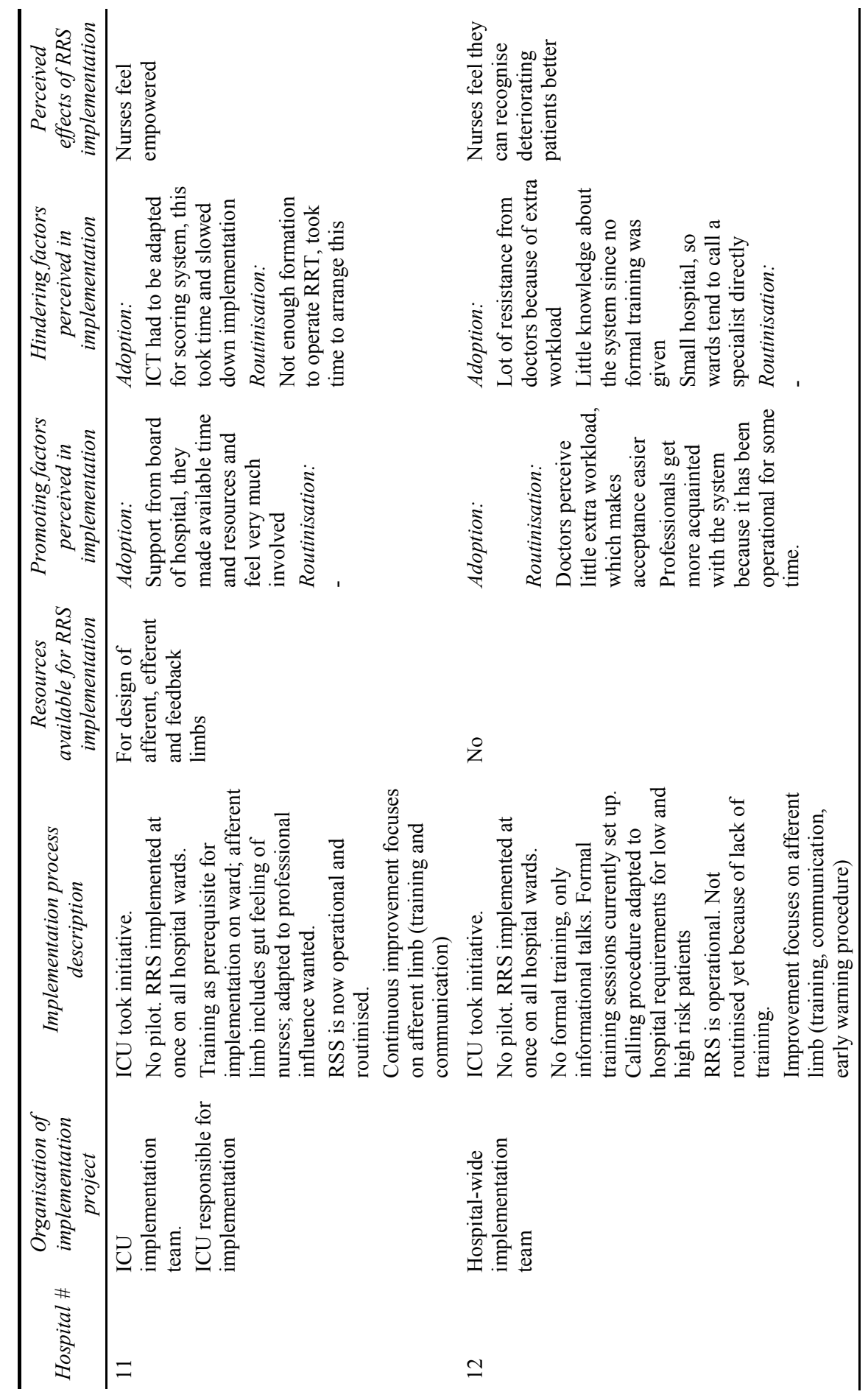


Table A1 Within-case analysis of RRS implementation (continued)

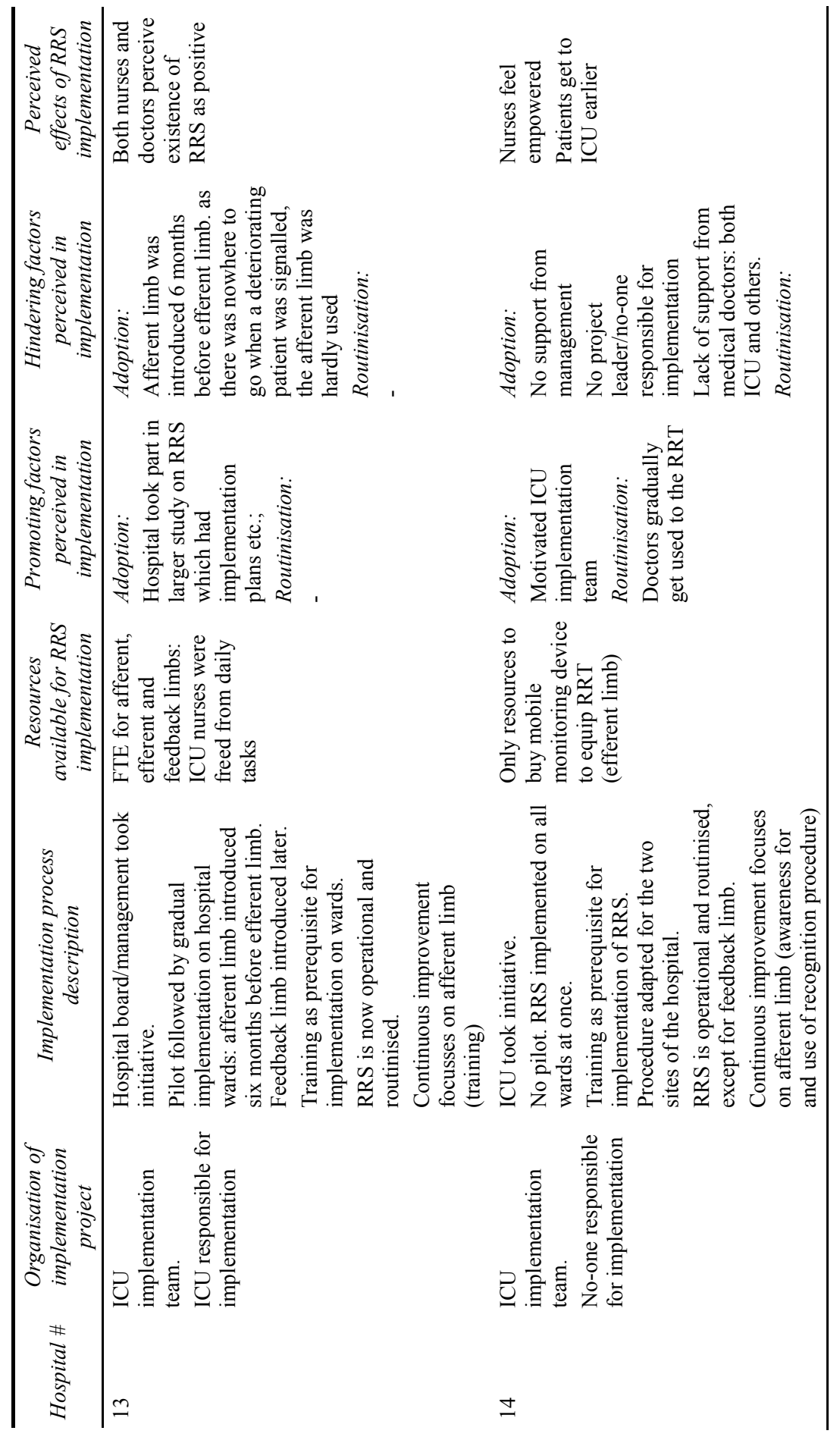


Table A1 Within-case analysis of RRS implementation (continued)

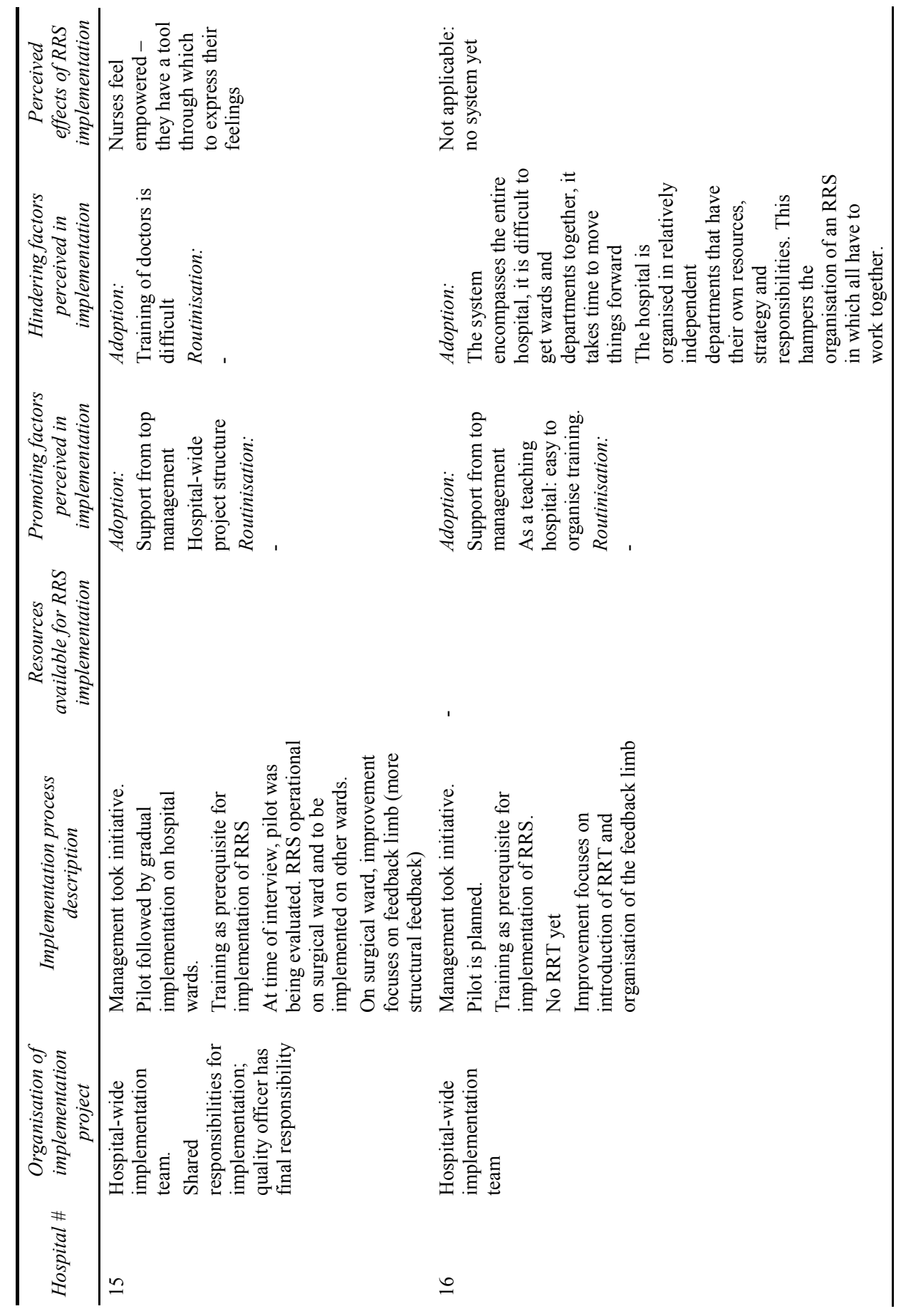


Table A1 Within-case analysis of RRS implementation (continued)

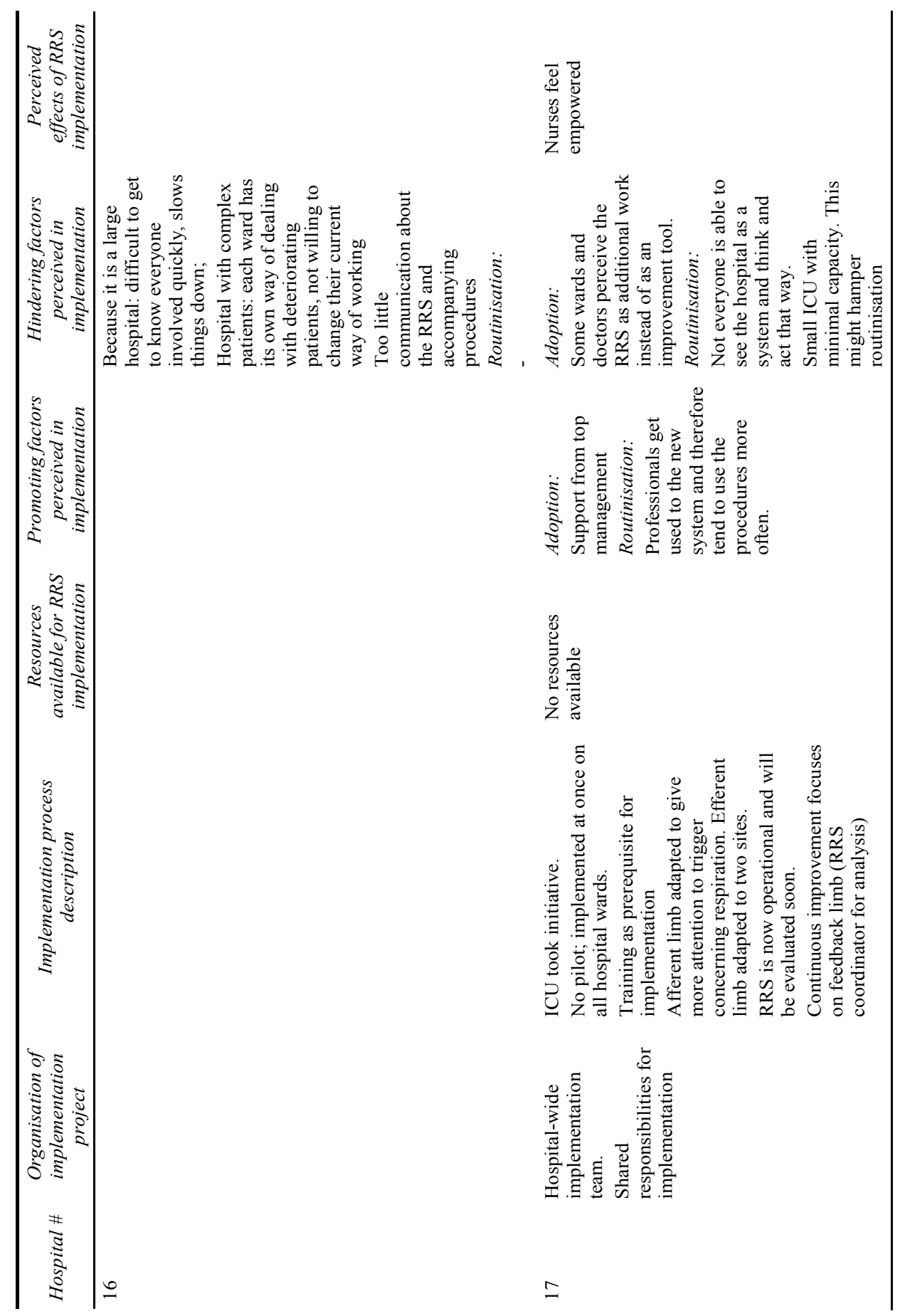


Table A1 Within-case analysis of RRS implementation (continued)

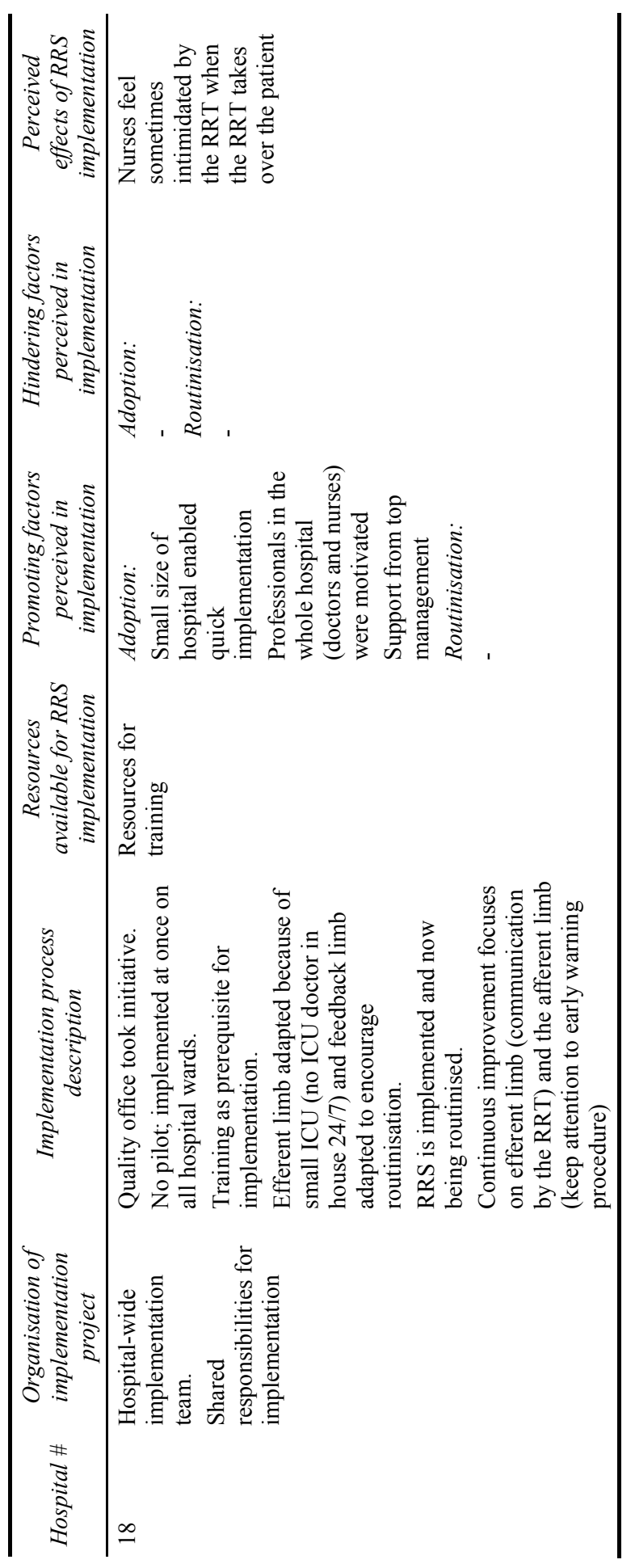




\section{Appendix B}

Table A2 Promoting and hindering factors perceived during the implementation process

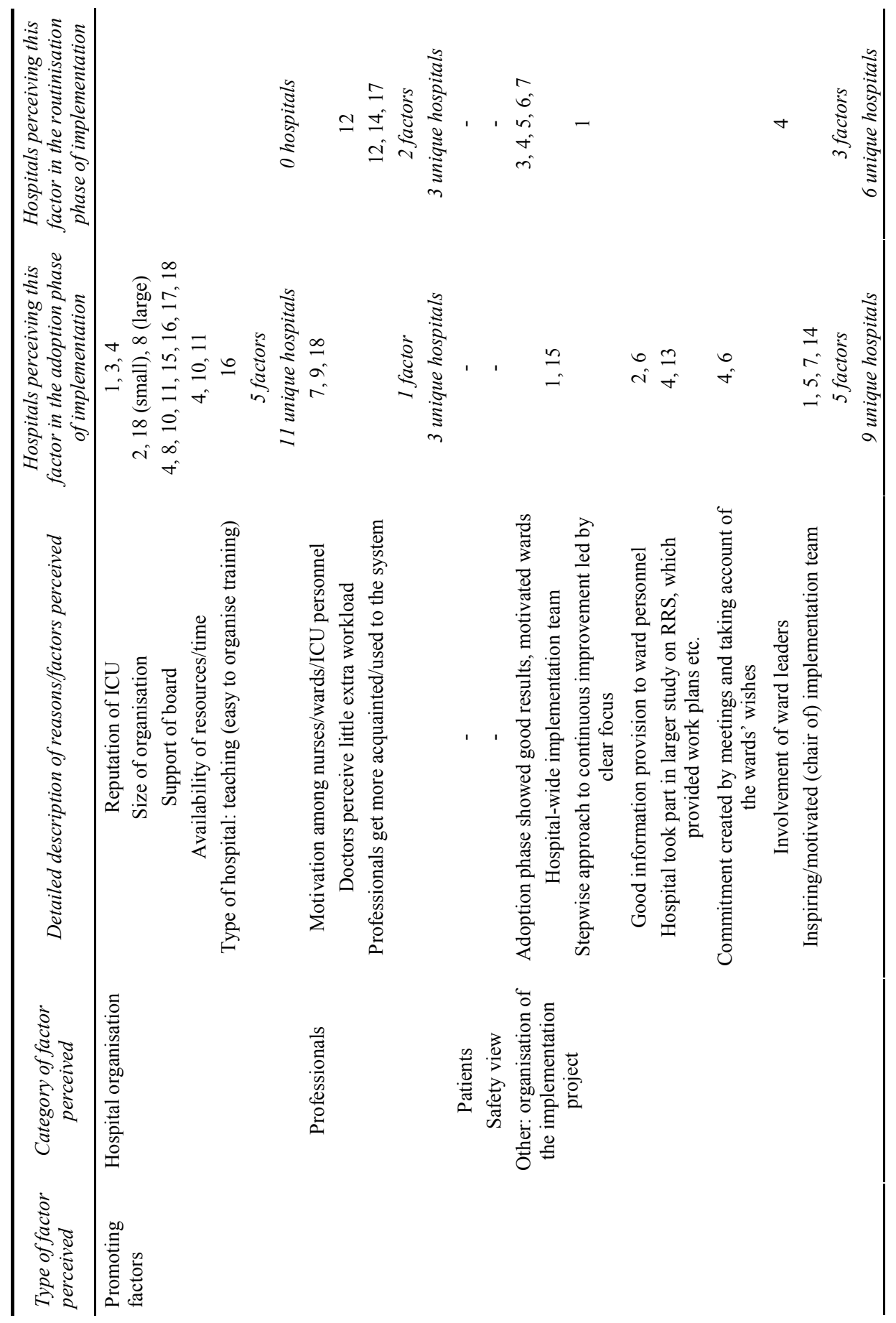


Table A2 Promoting and hindering factors perceived during the implementation process (continued)

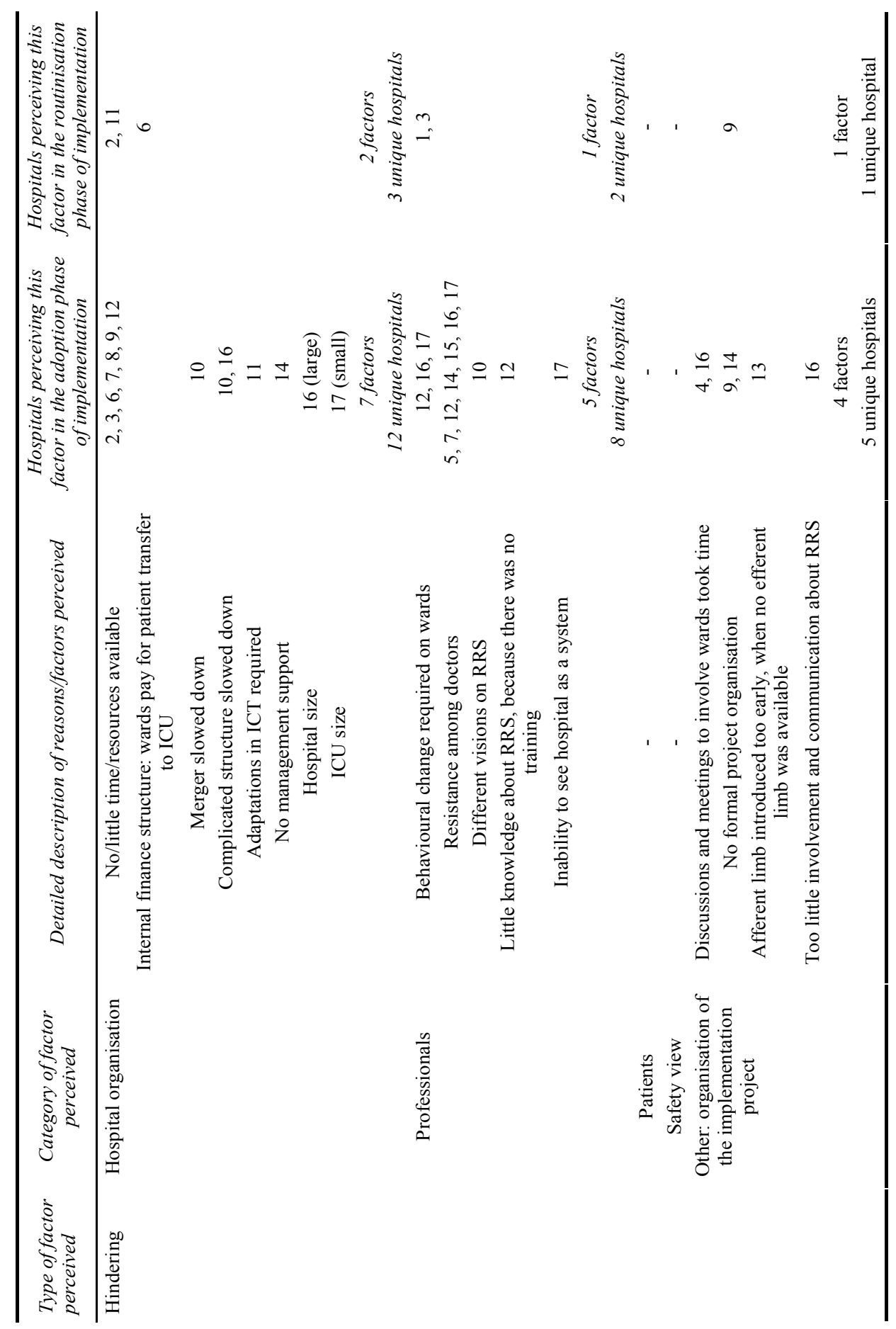

